\title{
Numerical modelingof first experiments on PbLi MHD flows in a rectangular duct with foam-based SiC flow channel insert
}

\author{
S. Smolentsev, ${ }^{1}$ C. Courtessole,,${ }^{1}$ M. Abdou, ${ }^{1}$ S. Sharafat,${ }^{1}$ S. Sahu, ${ }^{2}$ T. Sketchley ${ }^{1}$ \\ ${ }^{1}$ University of California - Los Angeles, USA, ${ }^{2}$ Institute of Plasma Research, India
}

\begin{abstract}
A flow channel insert $(\mathrm{FCl})$ is the key element of the DCLL blanket concept. The $\mathrm{FCl}$ serves as electrical and thermal insulator to reduce the MHD pressure dropand to decouple the temperature-limitedferritic structure from the flowing hot lead-lithium(PbLi) alloy.The main focus of the paperis on numerical computationsto simulateMHD flows in the first experiments on PbLi flows in a stainless steel rectangular duct with a foam-based silicon carbide ( $\mathrm{SiC}) \mathrm{FCl}$. A single uninterrupted long-term ( $6500 \mathrm{hrs}$ ) test has recently been performed on a CVD coated $\mathrm{FCl}$ sample in the flowing PbLi in a magnetic field up to $1.5 \mathrm{~T}$ at the PbLi temperature of $300^{\circ} \mathrm{C}$ in the MaPLE loop at UCLA. An unexpectedly high MHD pressure drop measured in this experiment suggests that a $\mathrm{PbLi}$ ingress into the $\mathrm{FCl}$ occurred in the course of the experiment, resulting in degradation of electroinsulating $\mathrm{FCl}$ properties. The ingress through the protective CVD layer was further confirmed by the post-experimental microscopic analysis of the $\mathrm{FCl}$. The numerical modeling included 2D and 3D computations using HIMAG, COMSOL and a UCLA research code to address important flow features associated with the $\mathrm{FCl}$ finite length, fringing magnetic field, rounded $\mathrm{FCl}$ corners and also to predict changes in the MHD pressure drop in the unwanted event of a $\mathrm{PbLi}$ ingress.Two physical/mathematical models have been proposed and 3D and 2D computations performed to explain theexperimental results. Although the computations do confirm that the $\mathrm{SiC} \mathrm{FCl}$ can significantly reduce the MHD pressure drop, these first testing resultsthat yet don't match the theoretical predictions, suggestthat more work on the $\mathrm{FCl}$ development and testing is still needed, first of all to ensure that the $\mathrm{FCl}$ can withstand $\mathrm{PbLi}$ ingress in a long run.
\end{abstract}

Keywords: DCLL blanket, flow channel insert, silicon carbide, lead-lithium, MHD flow

\section{Introduction}

A Dual-Coolant Lead-Lithium(DCLL) blanket is an attractive breeding blanket concept that leads to a high-temperature $\left(T^{\sim} 700^{\circ} \mathrm{C}\right)$, high thermal efficiency $(\eta>40 \%)$ blanket system [1].A flow channel insert $(\mathrm{FCl})$ is the key element in this blanket concept, which serves as an electrical insulator to reduce the magnetohydrodynamic (MHD) pressure drop in the lead-lithium (PbLi) flowsand also to decouple thetemperature-limited RAFM (reduced activation ferritic/martensitic steel) structure from the flowing high-temperature PbLi breeder (Fig. 1).

Historically, the first low-temperature (LT) DCLL blanket design[2]employed a"sandwich-type" FCI as an electrical insulator. This sandwich $\mathrm{FCl}$ consists of an insulating alumina layer embedded between two protecting layers of steel. In the more advanced high-temperature (HT) DCLL blanket [3], an FCl made of low-conductivity silicon carbide $(\mathrm{SiC})$ ceramics wasproposed for both electrical and thermal insulation.A sandwich-type $\mathrm{FCl}$ wastested in the past[4]. The tests demonstrated the anticipated reduction of the MHD pressure drop in MHD flows in a long duct subject to a transverse magnetic field. However, compared to a $\mathrm{SiC} \mathrm{FCl}$, the sandwich $\mathrm{FCl}$ has a smaller design window, is less effective as electrical insulator, and cannot serve as a thermal insulator. Also, the impact of corrosion on the protecting layers 
of steel and stability of insulating oxide ceramics in nuclear environment need to be addressed. At the same time, theexpected advantages of the $\mathrm{SiC} \mathrm{FCl,} \mathrm{e.g.significant} \mathrm{reduction} \mathrm{of} \mathrm{the} \mathrm{MHD} \mathrm{pressure} \mathrm{drop,}$ were demonstrated only in computations [5]. As a matter of fact,only one experimental study [6] has been conductedto characterize the effect of a mono-material $\mathrm{FCl}$ on the MHD pressure drop. However, in this experimentsubstitute materials were used: the $\mathrm{FCl}$ was made of epoxy and a room-temperature liquid metal galinstan was used as a working fluid. The results of this experiment were found to be different from the 2-D computational predictions [6], but later, a good match with the theory was demonstrated using a full 3-D computational model [7], suggesting importance of 3-D effects.

Besides computations in [5-7], there is a significant number of theoretical studies that address various aspects of $\mathrm{MHD}$ flowsin the presence of $\mathrm{FCls}$, includingeffectiveness of the $\mathrm{FCl}$ as electrical and thermal insulator[8-11],2-D and 3-D MHD effects[12-14], andinfluence of pressure equalization openings in the $\mathrm{FCl}$ on the MHD flow[15]. Tritium transport was considered in [16,17], while studies in Ref.[18] focused on impact of PbLi flows on corrosion of RAFM steel in the thin gap between the FCl and the RAFM structure. Pressure equalization mechanisms between the bulkPbLi flow inside the $\mathrm{FCl}$ box andthat in the thin gap betweenthe $\mathrm{FCl}$ and the RAFM wallwere considered in [19]. Performance of the DCLL blanket in ITER and DEMO was analyzed in[20], using electrical and thermal conductivity of the $\mathrm{FCl}$ asparameters.

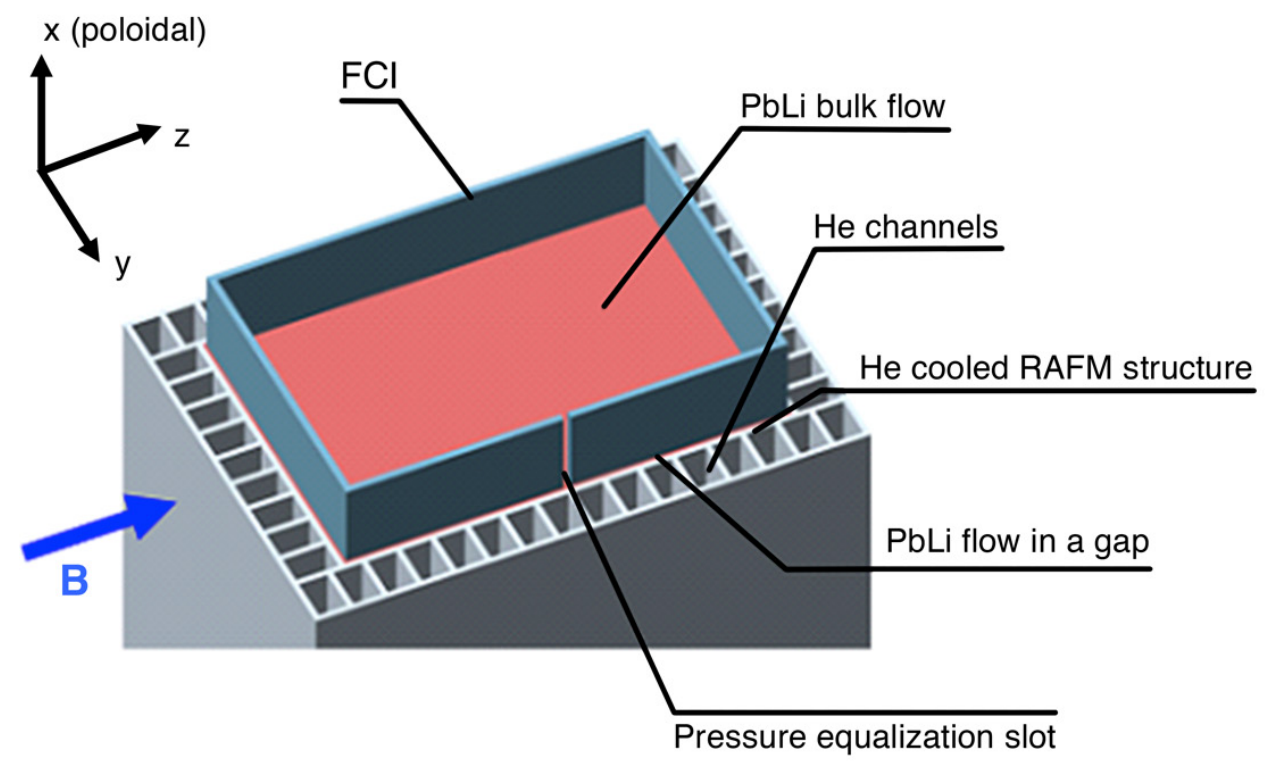

Figure 1. Schematics of the poloidal DCLL duct with the $\mathrm{FCl}$ and He-cooled structure. The $\mathrm{FCl}$ is seated loosely inside the RAFM duct forming a thin gap with the duct walls. Both the gap and the space inside the $\mathrm{FCl}$ have the flowing $\mathrm{PbLi}$ breeder/coolant. The $\mathrm{FCl}$ may have a pressure equalization slot or holes.

The requirements on SiC electrical and thermal conductivitieswere formulated in [20] and [21]based on the computational analysis of the velocity, pressure and temperature distributions for a $5-\mathrm{mm} \mathrm{FCl}$. As shown for the inboard DCLL blanket [21], the goal is low electrical conductivity of about $1 \mathrm{~S} / \mathrm{m}$. Higher electrical conductivities of about $50 \mathrm{~s} / \mathrm{m}$ are allowed for lower magnetic field outboard blankets[20]. When using such materials, MHD pressure drop reduction in poloidal flows by a factor of 50-100 is expected compared to bare ducts [5]. Good thermoinsulating properties of the $\mathrm{SiC} \mathrm{FCl}$ have been predicted as well providing the thermal conductivity is $1-2 \mathrm{~W} / \mathrm{m}-\mathrm{K}$ [20]. 
Two different approaches are currently considered to develop and manufacture SiC FClsof required thermomechanical properties, shapes and dimensions. In the first approach, a SiC $\mathrm{FCl}$ is reinforced with 2D fiber $\left(\mathrm{SiC}_{\mathrm{f}} / \mathrm{SiC}\right.$ composite) resulting in a relatively thin $\mathrm{FCl}$ wall of about $5 \mathrm{~mm}$. Such composites(see e.g. [22])can be produced by either chemical vapor infiltration (CVI) or using nano-infiltrated and the transient eutectic-phase (NITE) method. Another possible candidate for blanket applications is a foambased SiC FCI[23], which is a potential low-cost alternative to continuous fiber composite $\mathrm{FCl}$. The idea is to utilize a core of low-density SiC foam, sealed at all surfaces with a layer of CVD (chemical vapor deposition)SiC. A potential advantage of this coated foam-based SiC is low thermal and electrical conductivity. Using foam materials may, however, result in significantly thicker $\mathrm{FCls}$, displacing PbLi from the breeder region, and thus reducing the tritium breeding ratio (TBR).Also, such an $\mathrm{FCl}$ will likely have lower toughness and lower thermal shock resistance compared to what composites can offer. At present, SiC foam-based $\mathrm{FCl}$ segments with a $8 \mathrm{~mm}$ core and $\sim 1 \mathrm{~mm}$ thick CVD layers resulting in the overall $\mathrm{FCl}$ thickness of $1 \mathrm{~cm}$ have been successfully manufactured by Ultramet, USA (Fig.2).

(a)
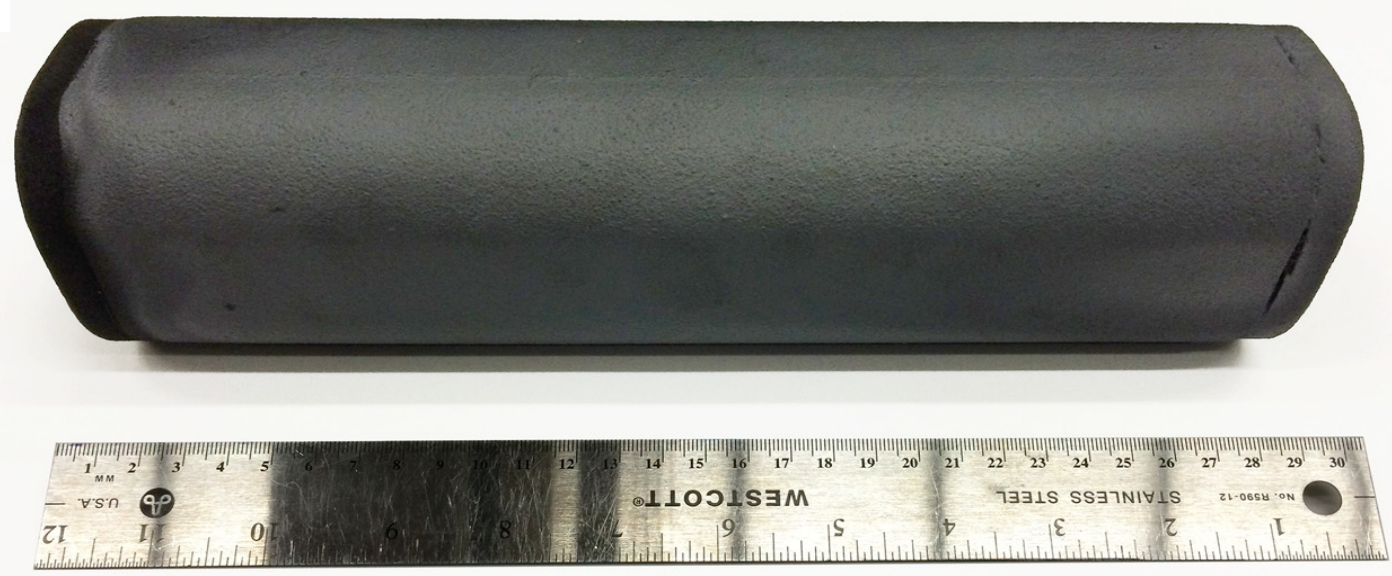

(b)
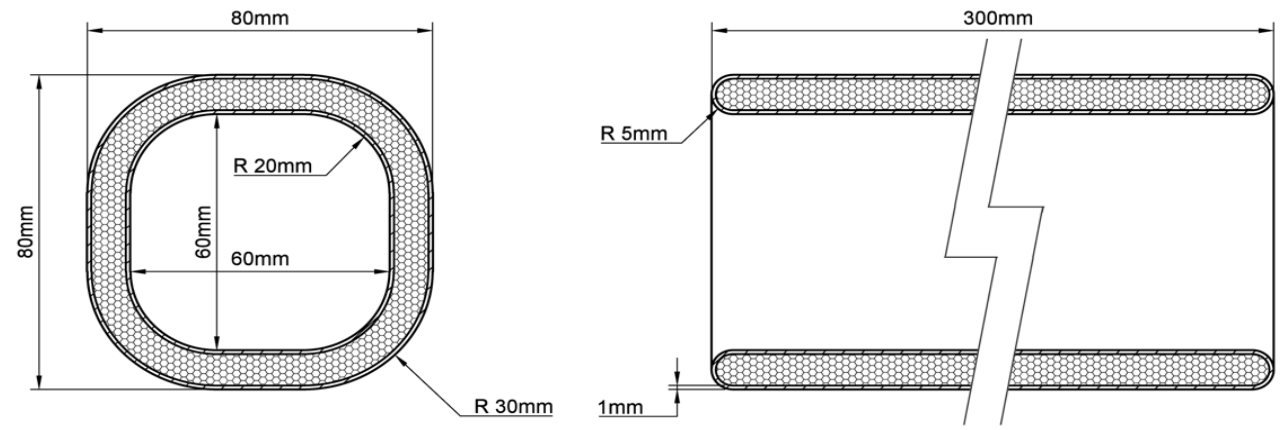

Figure 2. Foam-based SiC FCl manufactured by Ultramet, USA: (a) a 30-cm FCl segment and (b) overall $\mathrm{FCl}$ segment dimensions. 
Thinner foam-based $\mathrm{FCls}$ approaching 5-mm thickness seem to be possible in the future as the fabrication technology matures. As measured in [23] at room temperature in non-irradiation conditions, the electrical conductivity of foam-based SiCis $0.1-10 \mathrm{~s} / \mathrm{m}$ and thermal conductivity is $4-7 \mathrm{~W} / \mathrm{m}$ Kdepending on fabrication technique and surface pre-conditioning. A main concern about the use of $\mathrm{SiCmaterials} \mathrm{is,} \mathrm{however,} \mathrm{the} \mathrm{potential} \mathrm{for} \mathrm{ingress} \mathrm{of} \mathrm{PbLi}$ into the $\mathrm{FCl}$ through the cracks or other imperfections in the $\mathrm{FCl}$ that may appear in the manufacturing process or could develop when the $\mathrm{FCl}$ is exposed to hot PbLi and neutron irradiation.

Most of material testing performed earlier on $\mathrm{SiC}$ materials in isothermal conditions demonstrated that almost no physical/chemical interaction occurs between the SiC samples and PbLi, providing a special care was taken on purity of $\mathrm{PbLi}$, and providing no dissimilar materials were used in the experiment. For example, specimens of high purity SiC made by CVD showed very low mass change in the temperature range up to $1200^{\circ} \mathrm{C}$ using a CVD SiC capsule to prevent dissimilar material interactions [24]. When using a commercial PbLi eutectic alloy with a high oxygen content, no corrosion was observed either, instead a non-uniform oxide layer formed on the SiC surface resulting in the mass gain [25].Similar conclusions about stable behavior of $\mathrm{SiC}$ material in high-temperature PbLi were made more recently based on static testing of samples made of $\mathrm{CVD}$ coated $\mathrm{SiC}_{\mathrm{f}} / \mathrm{SiC}$ composite at $700^{\circ} \mathrm{C}$ [26]. In the case of dissimilar materials, e.g. the PbLi containing capsule is made of steel, a few experimental studies (unpublished) in a static pool of PbLi suggest that corrosion does occur. Quantitative data are however scarce and need further verification. To our knowledge, no data exist on corrosion of SiC materials in dynamic conditions when the PbLi is flowing.

In this study, we perform numerical studies of liquid metal MHD flows in a conducting rectangular stainless steel ducts with an $\mathrm{FCl}$ as a pre-experimental analysis. This includes computations for finitelength $\mathrm{FCl}$ segments exposed to MHD flows of PbLi in experimental-like conditions, where strong MHD effects and high MHD pressure drop can be present in the flow due to formation of 3D electric current loops associated with the $\mathrm{FCl}$ edges and a fringing (non-uniform) magnetic field. Additional numerical analysis addresses the effect of rounded $\mathrm{FCl}$ corners compared to the right-angle corners. These computations were performed using three numerical codes: HIMAG [28] developed jointly by HyPerComp, USA and UCLA, the commercial finite-element software COMSOL Multiphysics [29] and a UCLA multi-material research code for fully developed MHD flows [30]. The experimental part of the study included dynamic FCl testing in the MaPLE loop at UCLA [27]. In these dynamic tests, the MHD pressure drop was measured over the flow section with the $\mathrm{FCl}$ and then compared with the pressure drop measured over the bare duct section to evaluate the pressure drop reduction factor.Surprisingly, the experimental data demonstrated higher MHD pressure drops compared to the theoretical predictions, suggesting that significant $\mathrm{PbLi}$ ingress in the $\mathrm{FCl}$ occurred in the course of the experiment. This ingress was further confirmed with the microscopic analysis. To better interpret the experimental data, in particular to understand what might cause the PbLi ingress, the experimental data were compared against the post-experimental numerical analysis, where two possible scenarios of the PbLi ingress were considered.

\section{Theoretical background of MHD flows with $\mathrm{FCl}$}

Depending on the length of the insert with respect to the host duct, there can be two different approaches to attacking the MHD problem of PbLi flows in a rectangular duct with $\mathrm{FCls}$ in a magnetic field. The first approachassumes a long duct with an $\mathrm{FCl}$ extended over the whole duct length,all in a uniform magnetic field. In such conditions, 3-D effects associated with the developing flows at the duct inlet/outlet or those due to a fringing magnetic field can be neglected, such that the problem can be treated as anentirely 2-D problem, using a fully-developed flow model. In fact, such a flow model is a 
close approximation to the real DCLL blanket conditions where the $\mathrm{FCl}$ segments are placed continuously inside the long poloidal ducts(not counting for overlap regions between two $\mathrm{FCl}$ segments). If so, the dominating electrical currents are those closing in the cross-sectional plane (cross-sectional currents) as shown in Fig. 3.
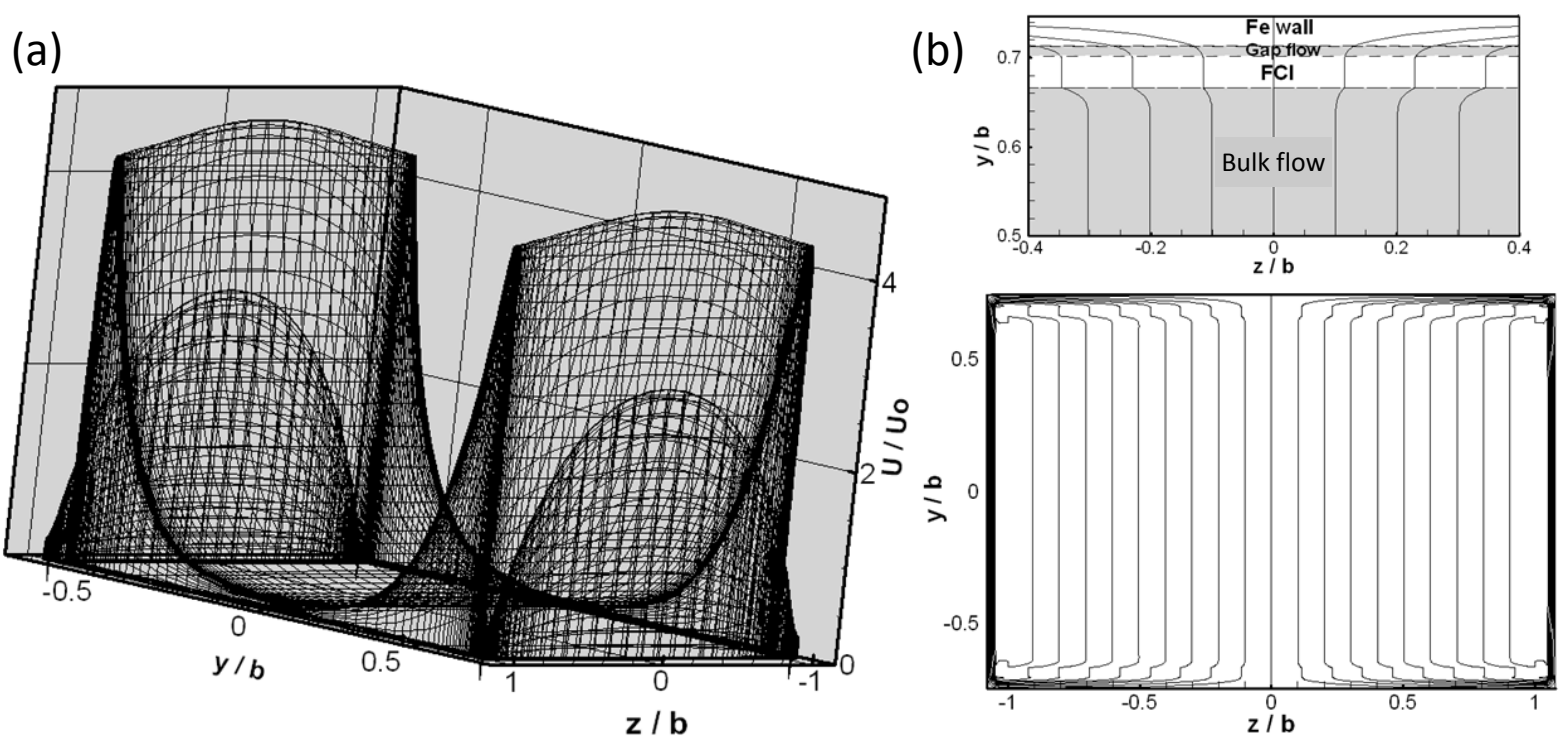

Figure 3. Fully developed MHD flow in a rectangular duct with insulating $\mathrm{FCl}$ with no pressure equalization openings computed at $H a=15,900$ and $\sigma_{F C I}=100 \mathrm{~S} / \mathrm{m}:$ (a) velocity profile, (b) induced electric current.

In this figure, the MHDPbLi flow was computed with the numerical code described in [30] for a duct made of RAFM steel at the Hartmann number $\mathrm{Ha}=15,900$ and the electrical conductivity of the $\mathrm{FCl} \sigma_{F C I}$ of $100 \mathrm{~S} / \mathrm{m}$, assuming no pressure equalization openings in the $\mathrm{FCl}$.The Hartmann number is defined as $H a=B_{0} b \sqrt{\sigma / v \rho}$, where $B_{0}$ is the applied magnetic field, $b$ is the half of the distance between the two $\mathrm{FCl}$ walls perpendicular to the magnetic field, and $\sigma, v$ and $\rho$ are the electrical conductivity, kinematic viscosity and the density of PbLi correspondingly. The associated reduction in the MHD pressure drop in such a fully developed flow compared to a bare duct could be up to 100 times as shown in [5] for lowconductivity FCls.

The second approach is more related to experimental conditions (e.g. [6]), where a purely 2-D flow can hardly be established because of the limited workspace inside the magnet and other experimental constraints. In such conditions, axial electrical currents are induced at some locations along with the cross-sectional currents, such that the MHD pressure drop associated with the 3-D effects is not negligible any more. Typically, this 3-D MHD pressure drop is comparable with or even considerably higher than the 2-D MHD pressure drop in a fully-developed flow.A computed pressure distribution in thePbLi flow with a finite-length $\mathrm{FCl}$ is shown inFig. 4. In this computation, the $\mathrm{FCl}$ is $60-\mathrm{cm}$ long, while the length of the host duct is $2 \mathrm{~m}$. The $\mathrm{FCl}$ and the host duct form a small 2-mm gap between them, which is also filled with PbLi. In the original DCLL concept, the gap was proposed in order to accommodate possible $\mathrm{FCl}$ thermal expansion and to avoid mechanical stresses in the $\mathrm{FCl}$ by allowing it to freely float in the liquid. ThisPbLi flow in the duct with the $\mathrm{FCl}$ is subjected to a spatially-varying magnetic field analogous to that in the MaPLE loop at UCLA [27], which is equipped with an airgapmagnet that produces maximum magnetic field of $1.8 \mathrm{~T}$ over the $80-\mathrm{cm}$ length. There are two 
fringing field regions at the edges of the magnet as also shown in the figure. The computation is performed at the flow velocity $U_{0}$ of $5 \mathrm{~cm} / \mathrm{s}$, which is close to that in a DCLL blanket (see, e.g. [1]) and the magnetic field of $1.5 \mathrm{~T}$. The corresponding dimensionless Reynolds number $\left(\operatorname{Re}=U_{0} b / \mathrm{v}\right)$ is 11,000 and the Hartmann number is 1350 .
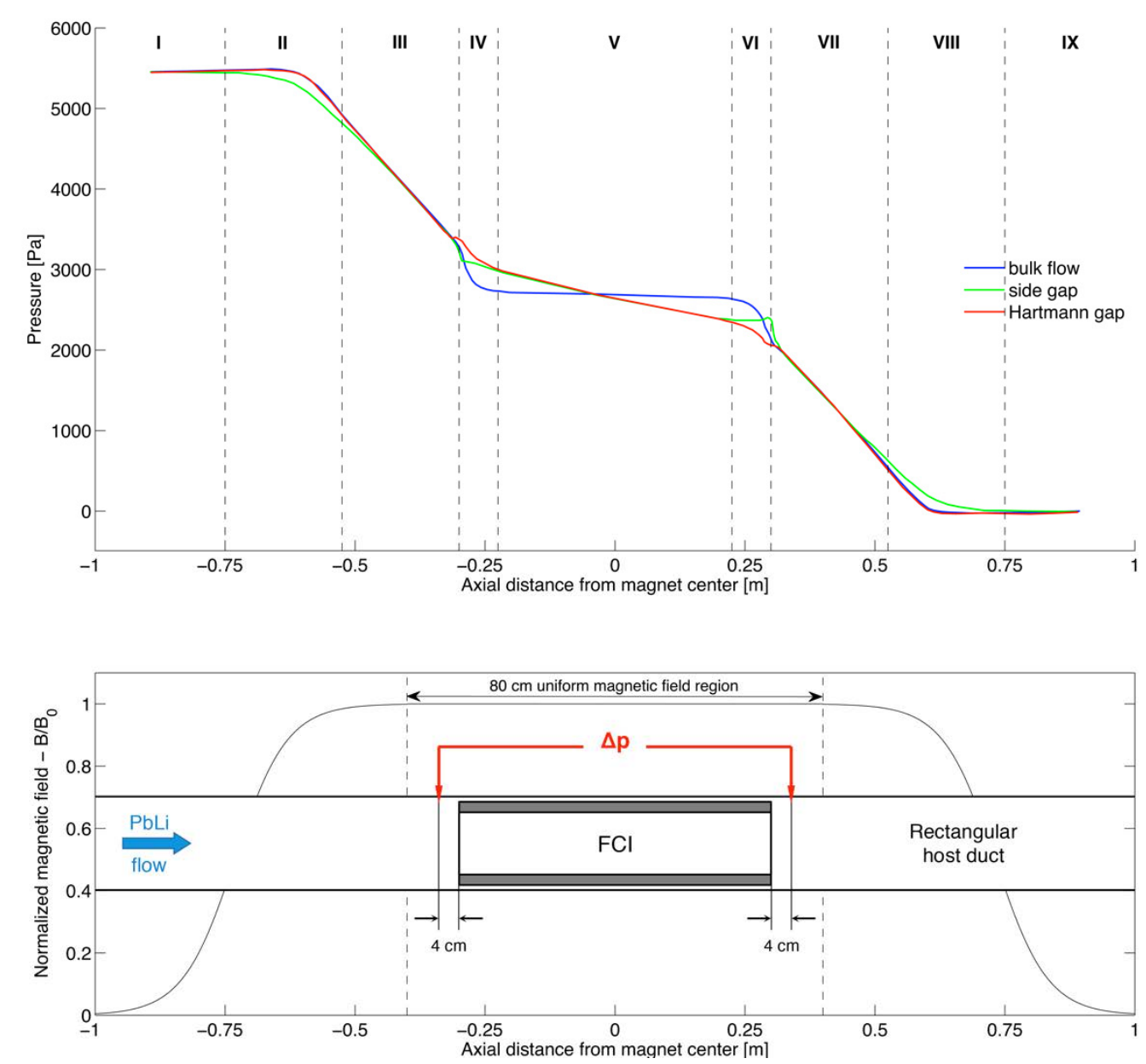

Figure 4. 3D MHD PbLi flow in a rectangular duct with $\mathrm{FCl}$ at $H a=1350\left(B_{0}=1.5 \mathrm{~T}\right), R e=11,000\left(U_{0}=5\right.$ $\mathrm{cm} / \mathrm{s}$ ), $\sigma_{F C I}=1 \mathrm{~S} / \mathrm{m}$ : (top) axial pressure distribution at three locations, (bottom) location of the host steel duct with the $\mathrm{FCl}$ with respect to the magnetic field.

The pressure in Fig. 4is plotted as a function of the axial distance at three locations: one is at the ductcenter and the other two are in the 2-mm gap at the center of theHartmann wall and at the center of the side wall. As indicated in the figure, the pressure distribution has nine characteristic zones with respect to the axial distance. In zones I,III,V,VII and IX the flow is fully developed (or almost fully developed) as seen from the linear pressure dependency of the axial distance and also due to the fact that the pressure at three different locations within the same cross-section is the same. The only exception is zone $\mathrm{V}$, associated with the flow over the duct section with the $\mathrm{FCl}$. Here, the pressure is also linearly varying with the axial coordinate but there is some difference in the pressure between the bulk and the gap. This difference is because the two flows are completely decoupled as the $\mathrm{FCl}$ in this particular example is almost ideally insulating. The pressure drop in the gap is significantly higher than 
that in the bulk flow inside the $\mathrm{FCl}$ box. In zones II, IV, VI and VI, the pressure demonstrates significant variations over the cross-section. This, and also the non-linear pressure dependency of the axial coordinate suggest that the flow in these zones is 3D. The 3D effects in zones II and VIII are related to the fringing magnetic field, whereas in zones IV and VI, the 3D effects are associated with the entry/exit flow effects at the $\mathrm{FCl}$ edges.

To quantitatively describe differences in the pressure drop between the MHD flows with and without the $\mathrm{FCl}$ it is useful to introduce a pressure drop reduction factor $R$ (R-factor). Following [5], the R-factor is defined as the ratio of the MHD pressure drop in a bare duct without an $\mathrm{FCl}$ relative to that with the $\mathrm{FCl}$. It is also reasonable to distinguish between the pressure drop reduction factor in a fully developed flow $R_{2 \mathrm{D}}$ and that for a flow with a finite-length $\mathrm{FCl} R_{3 \mathrm{D}}$. As mentioned earlier in the paper, providing the $\mathrm{FCl}$ electrical conductivity is low enough, $R_{2 \mathrm{D}}$ could be as high as $\sim 100$ in blanket flows, while $R_{3 \mathrm{D}}$ is sufficiently lower due to the contribution of 3-D effects as shown in Section 4.

\section{Pre-experimental numerical analysis using HIMAG}

Prior to dynamic testing where an $\mathrm{FCl}$ sample was exposed to the flowing $\mathrm{PbLi}$ in a magnetic field, static tests were performed on several coated and uncoated $\mathrm{FCl}$ samples in a pool of stagnant PbLi. The important details and main conclusions of this study are presented in Ref. [1].In these static tests, several $12-\mathrm{cm} \mathrm{FCl}$ sampleswere exposed to a stagnant (not counting possible natural-convection flows) $\mathrm{PbLi}$ at the temperature of $700^{\circ} \mathrm{Cfor} 100$ hours at different Ar gas overpressures from 0.1 to $1 \mathrm{MPa}$. About half of these tests demonstrated no PbLi ingress, others had some ingress from small to significant. More ingress was observed in the uncoated samples.

As a pre-experimental analysis of the dynamic experiments, full 3D computations were performedusing the HIMAG code [28] to estimate typical values of thepressure drop reduction factor $R_{3 \mathrm{D}}$ under the experimental conditions. The second goal of the pre-experimental analysis was to define optimal locations of the two pressure taps, which are used in the experiment to measure the pressure drop over the $\mathrm{FCl}$ segment.Ideally, these two pressure taps should be located within the fully developed flow section, i.e. within zone $\mathrm{V}$ as shown in Fig. 4. In practice, placing the pressure taps within the fully developed flow region would require two orifices in the $\mathrm{FCl}$. This is definitely prohibited because of a high risk of PbLi ingress at these two locations. Because of this reason, it was decided to have the pressure taps located at some distance from the fore and rear edges of the $\mathrm{FCl}$ as shown in Fig. 4 at the bottom. Putting the pressure taps too far from the $\mathrm{FCl}$ would increase the measured MHD pressure drop and thus complicate the analysis of the experimental data. Contrary, putting them too close to the $\mathrm{FCl}$ edges would result in uncertainties in measurements of the pressure drop since the pressure distribution near the $\mathrm{FCl}$ edges is not uniform, i.e. the pressure is different between the Hartmann and the side layers and both are different from that in the bulk flow. As a compromise, based on the preexperimental analysis, the distance of $4 \mathrm{~cm}$ was found to be optimal for almost all parameters from the experimental matrix.

The experimental matrix includes three magnetic field strengths $(0.5,1.0$ and1.5T) and three velocities $(5,10$ and $15 \mathrm{~cm} / \mathrm{s})$. In addition, computations were performed for $1.8 \mathrm{~T}$. The $\mathrm{FCl}$ and the host duct parameters are given in Section 5. Computational results from this pre-experimental analysis have been summarized in Table Ifor all the velocities and magnetic field strengths. As seen from this table, the Rfactor increases with the magnetic field and slightly decreases with the velocity. Based on the computed $\mathrm{R}$-factor, the reduction of the MHD pressure drop by the $\mathrm{FCl}$ in the experiments was expected to be around 1.5 compared to a bare duct flow of the same length. Surprisingly, the experimental results werefound to be significantly different from the theoretical predictions (much lower R-factor) as explained in detail in Section 5. It has to be mentioned that in the pre-experimental computations, 
rounded $\mathrm{FCl}$ corners (see Fig. 2c) were not included. Rather than that, the computational model used approximated right-angled corners. The rounded $\mathrm{FCl}$ corners were added in the post-processing computations (see Section 6), but the obtained results were not very different from the results of the pre-experimental analysis and thus the discrepancybetween the experimental data and the theoretical predictions of the pre-experimental analysis cannot be explained with the simplified $\mathrm{FCl}$ geometry used in the pre-experimental computations.

Table I. Pre-experimental analysis. Pressure drop reduction factor computed with HIMAG versus Hartmann number, Reynolds number and interaction parameter for $\sigma_{F C I}=5 \mathrm{~S} / \mathrm{m}$.

\begin{tabular}{|c|c|c|c|c|}
\hline$U_{0}(\mathrm{~cm} / \mathrm{s}) / R e$ & $\Delta P_{\text {bare }}(\mathrm{Pa})$ & $\Delta P_{\mathrm{FCl}}(\mathrm{Pa})$ & $\boldsymbol{R}_{3 \mathrm{D}}$ & $N=H a^{2} / R e$ \\
\hline \multicolumn{5}{|c|}{$B=0.5 \mathrm{~T}(\mathrm{Ha}=448)$} \\
\hline $5 / 11350$ & 305.9 & 259.2 & 1.18 & 17.7 \\
\hline $10 / 22700$ & 614.9 & 587.1 & 1.05 & 8.84 \\
\hline $15 / 34050$ & 922.4 & 895.5 & 1.03 & 5.89 \\
\hline \multicolumn{5}{|c|}{$B=1.0 \mathrm{~T}(H a=895)$} \\
\hline $5 / 11350$ & 1190.8 & 815.3 & 1.46 & 70.6 \\
\hline $10 / 22700$ & 2381.6 & 1743.9 & 1.37 & 35.3 \\
\hline $15 / 34050$ & 3594.4 & 2758.5 & 1.30 & 23.5 \\
\hline \multicolumn{5}{|c|}{$B=1.5 \mathrm{~T}(H a=1342)$} \\
\hline $5 / 11350$ & 2677.1 & 1620.0 & 1.65 & 158 \\
\hline $10 / 22700$ & 5302.6 & 3486.9 & 1.52 & 79 \\
\hline $15 / 34050$ & 8014.1 & 5387.6 & 1.49 & 52.7 \\
\hline \multicolumn{5}{|c|}{$B=1.8 \mathrm{~T}(H a=1611)$} \\
\hline $5 / 11350$ & 3856.0 & 2227.9 & 1.73 & 229 \\
\hline $10 / 22700$ & 7684.3 & 4763.2 & 1.61 & 114 \\
\hline $15 / 34050$ & 11530.5 & 7420.0 & 1.55 & 76.3 \\
\hline
\end{tabular}

In the table, $U_{0}$ is the mean bulk velocity in the bare duct and the Hartmann and Reynolds numbers aredefined earlier in Section 2. As seen from the table, all flows in the simulations (and also in the experiment) are high Hartmann number, high interaction parameter flows, meaning that electromagnetic forces are much stronger compared to viscous and inertia forces. Also, theratio Re/Ha, which is the Reynolds number based on the thickness of the Hartmann layer is below its critical magnitude of about 200-400. Another relevant ratio $\mathrm{Re} / \sqrt{\mathrm{Ha}}$ (Reynolds number based on the thickness of the side layer) that can be used to predict instabilities in the side layers is above its critical value of about 65 (see, e.g. [32]) in almost all experiments. These suggest that the flow in the Hartmann layers in the experiments is laminar but the side-wall jets, which are formed at the duct walls parallel to the applied magnetic field, are most likely unstable such that quasi-two-dimensional turbulence [32] is likely to occur.

\section{MaPLE loop}

The MaPLE loop (Fig. 5), which was used for dynamic testing, includes a pipe system, electromagnetic (EM) pump, EM flow meter, electromagnet and a glove box. The flow circuit that consists of themelting tank (also serves as a supply/drain tank) and pipelines, are made of stainless steel SUS304. The 
maximum inventory of PbLi in the loop is about $250 \mathrm{~kg}$. The style V EM conduction pump by Creative Engineers, Inc., USA is used for pumping the alloy through the circuit. The pump tube is made of stainless steel SUS316. The loop is currently operated at maximum temperature of $350^{\circ} \mathrm{C}$ as required by the temperature limit of the pump. The magnetic field is created by a water-cooled air-gap electromagnet with the maximum magnetic field of $1.8 \mathrm{~T}$. The magnetic field is uniform within the space of $80 \mathrm{~cm}$ (axial) $\times 15 \mathrm{~cm}$ (horizontal) $\times 15 \mathrm{~cm}$ (vertical).

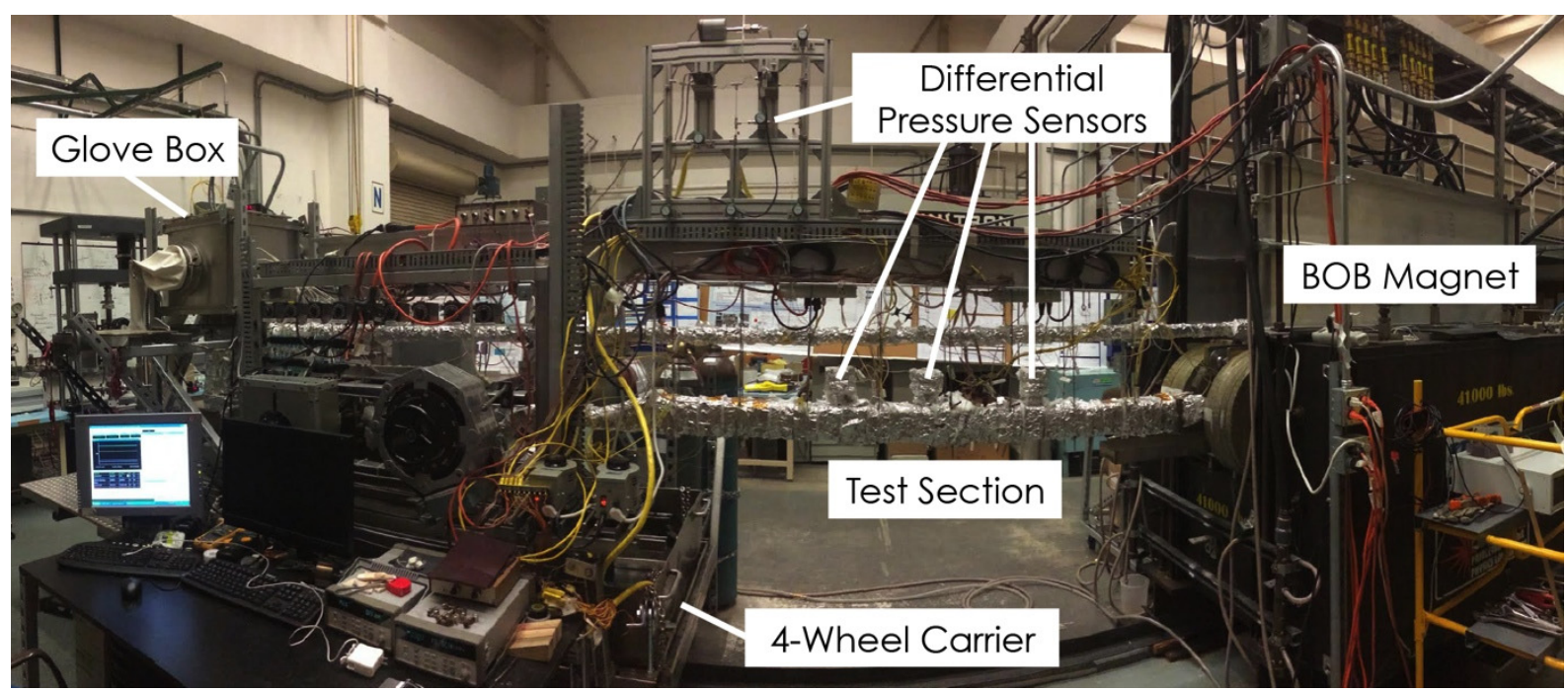

Figure 5.Panoramic picture of the MaPLE loop at UCLA used for dynamic testing of the $\mathrm{FCl}$ sample in the flowing PbLi in a magnetic field.

The whole loop, except for the magnet, sits on a steel catch pan, which in turn is put on a four-wheel carrier, which can be moved forward or backward. This allows for all the maintenance work on the loop components to be done outside the magnet. To keep the alloy above its melting point $\left(234^{\circ} \mathrm{C}\right)$, the melting tank is heated by band-heaters and the piping and test section by rope-heaters. There are eight independent, individually controlled heater sections. The tubing part inside the EM pump is heated by its built-in heater and also due to parasitic Joule heating when the conduction pump is on. All loop components are thermally insulated and heated. The glove box that sits on the top of the melting tank is designed to allow for a connection of a vacuum pump and/or a purification unit for circulation of highpurity argon gas through the loop in the initial loop operation stages to remove air and moisture. Figure 5 shows a panoramic picture of the loop taken at the time of writing this paper.

\section{Dynamic testing}

A $90 \mathrm{~mm} \times 90 \mathrm{~mm} \times 1848 \mathrm{~mm}$ host stainless steel (SUS304) duct with 3-mm walls (Fig. 6a) was fabricated at UCLA and the FCl was placed inside the duct as shown in Fig. $6 \mathrm{~b}$. The position of the SiC insert inside the host duct is fixed with several adjustable pin holders. There are pin holders to center the $\mathrm{FCl}$ inside the host duct and also to restrict vertical and horizontal $\mathrm{FCl}$ displacements (centering pins) and those to restrict axial displacements in the flow direction (restrain pins) as shown in Fig. 7. The minimal gap between the $\mathrm{FCl}$ and the wall of the host duct is $2 \mathrm{~mm}$ with bigger gap spacing at the corners because of the rounded $\mathrm{FCl}$ shape. Three pressure taps are welded to the duct to connect the indirect pressure measurement systemalready used in [28]. This system measures a differential pressure betweentwo argon-filled pressure cans, each connected to its pressure tap with a thin tube as described 
in [28]. The location of the pressure taps is shown schematically in Fig. 8. Before placing the $\mathrm{FCl}$ insight the host duct, the $\mathrm{FCl}$ was weighed at $780 \pm 1 \mathrm{~g}$.

(a)

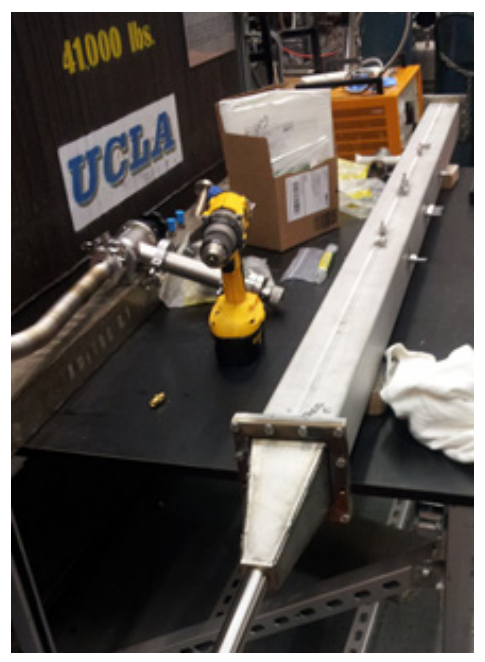

(b)

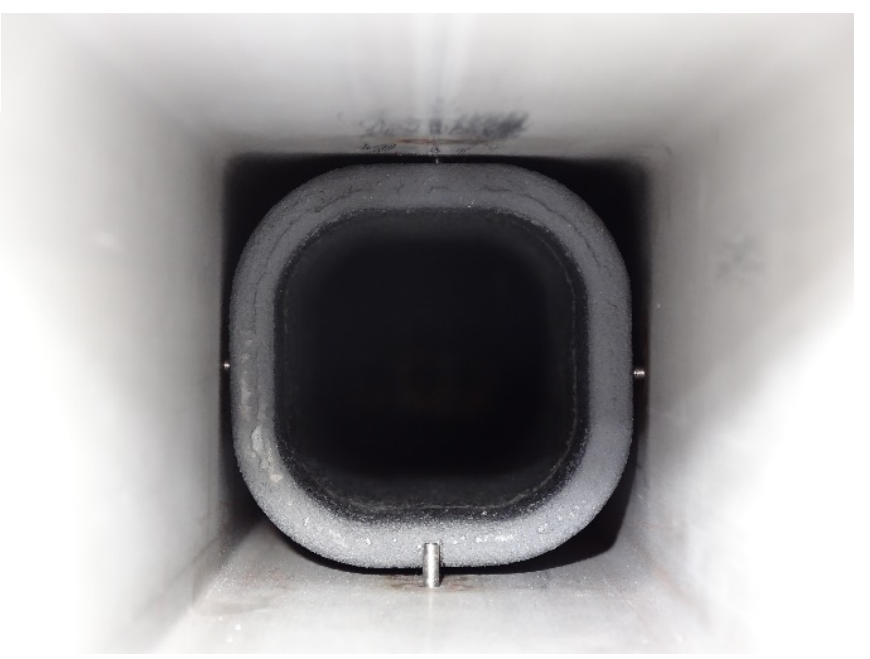

Figure 6. Experimental test section: (a) host stainless steel duct and (b) location of the $\mathrm{FCl}$ inside the host duct.

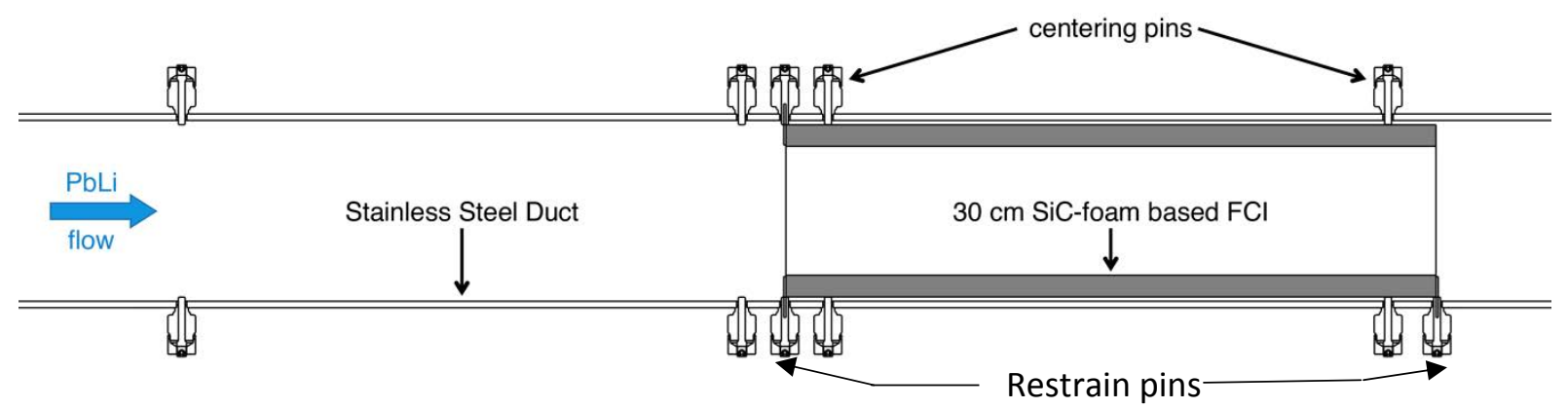

Figure 7. Location of centering and restrain pins to fix the position of the $\mathrm{FCl}$ segment inside the host duct.

After melting PbLi ingots from Atlantic metals, USA in the melting tank and filling the loop with the liquid metal, the test section was moved in the gap space of the magnet and experiments on measuring the pressure drop over the $\mathrm{FCl}$ and bare duct sections started. When preparing the melt, special care was taken on removing oxygen, which is originally present in the ingots. This was done by continuous pumping of high-purity argon gas through the melting chamber for many hours. This cleaning procedure results in a very small content of oxygen of only $\sim 5 \mathrm{ppm}$ in the cover argon gas. However, no oxygen monitoring was performed during the experiments. Completing the measurements took unexpectedly long time about 9 months ( $6500 \mathrm{hrs}$ ) because of some faults in the pressure measurement system, caused by clogging the connection tubes between the duct and the argon-filled pressure cans, such that the pressure measurements were taken only in the last month of the 9-month experimental period after fixing all faults in the pressure system. In the early stage of the experiment ( $<800 \mathrm{hrs}$ ), the pressure drop over the $\mathrm{FCl}$ segment was evaluated indirectly by calculating pressure drops for all loop components 
(except for that over the $\mathrm{FCl}$ section) and then subtracting them from the overall pressure drop in the lo

$\mathrm{m}$

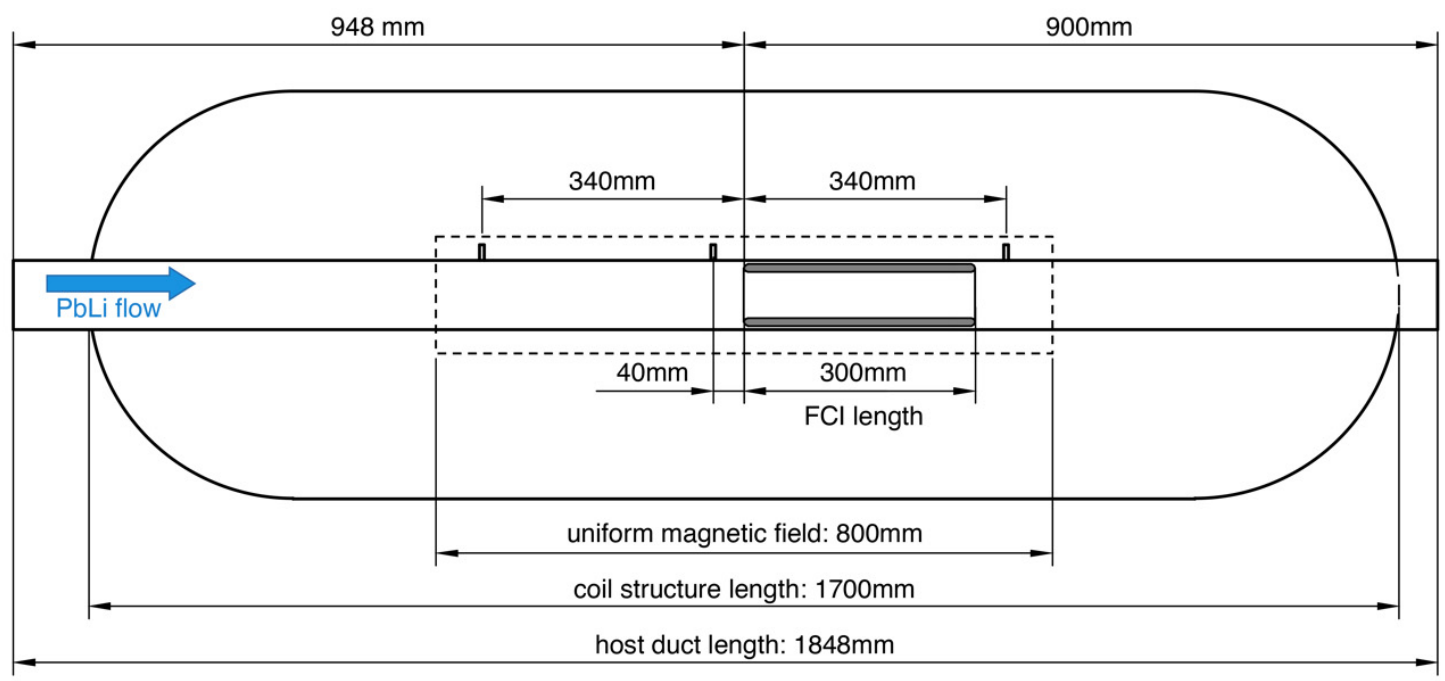

Figure 8. Location of the $\mathrm{FCl}$ and the host duct with respect to the magnet (shown with a dotted line). The figure also shows locations of three pressure taps.

The direct pressuremeasurements were taken first without the magnetic field and then at three magnetic field strengths: $0.5,1.0$ and $1.5 \mathrm{~T}$. The flow velocity was also widely varied by changing the pump voltage from 20 to $240 \mathrm{~V}$. The maximum flow-rate in the experiments was $38 \mathrm{LPM}$. This corresponds to the velocity of $0.09 \mathrm{~m} / \mathrm{s}$ in the host duct, and $1.6 \mathrm{~m} / \mathrm{sin}$ the one-inch connecting circular pipes. The PbLi temperature in the experiments was held at $\sim 300^{\circ} \mathrm{C}$. The maximum pressure in the loop did not exceed $0.25 \mathrm{MPa}$.

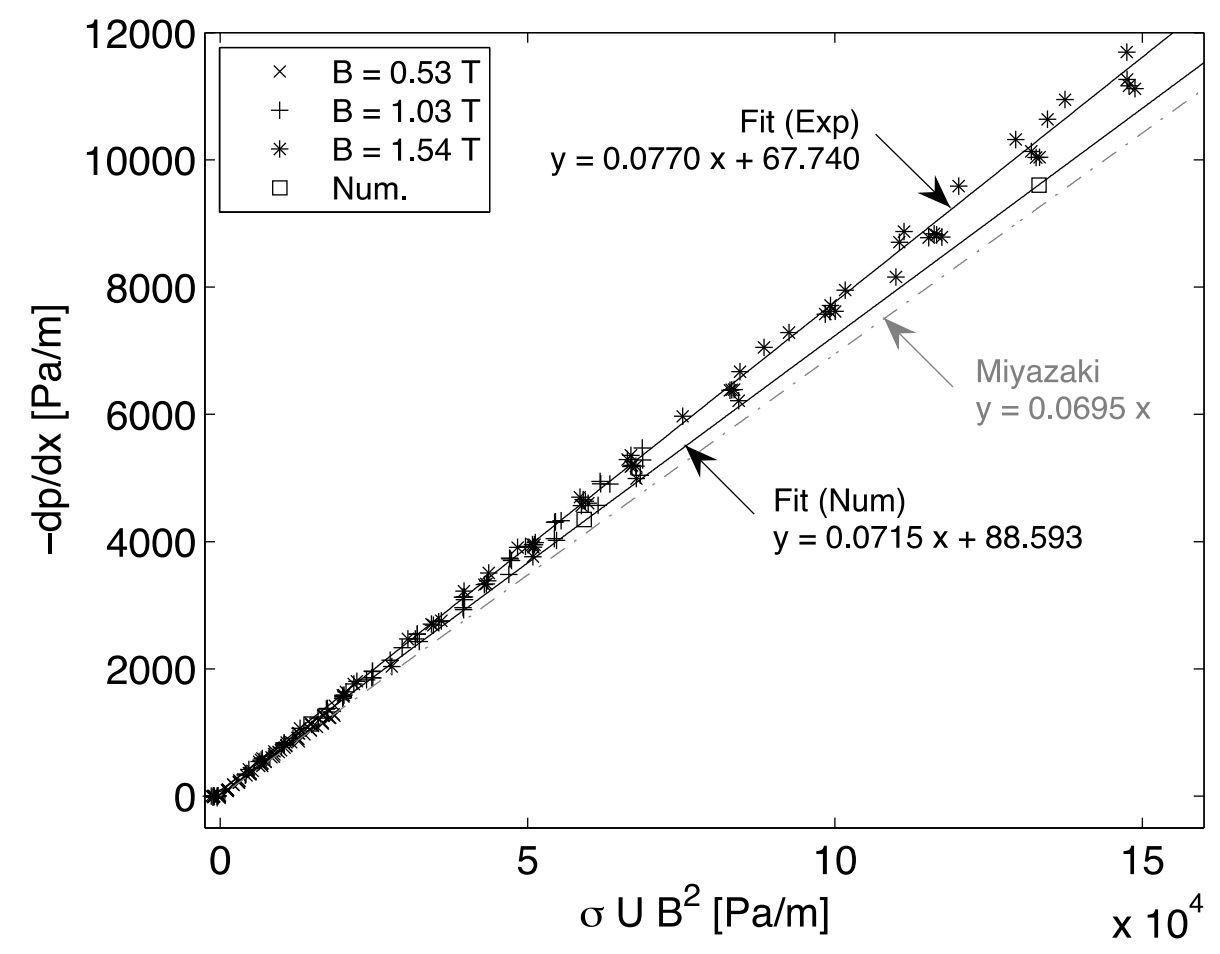

Figure 9. Pressure drop in PbLi in the bare duct. 


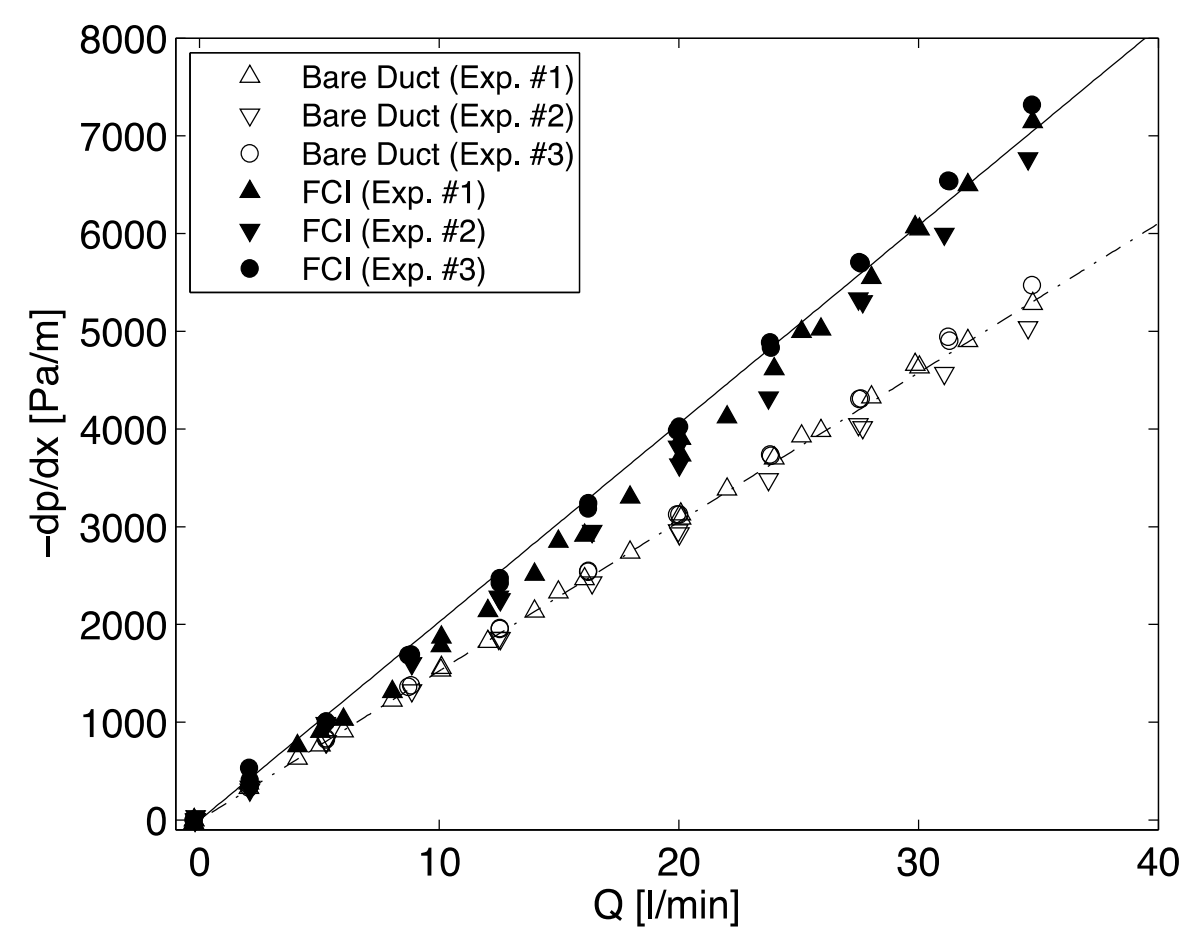

Figure 10. Comparison for the MHD pressure drop with and without the $\mathrm{FCl}$ at $1 \mathrm{~T}$.

The main goal of this series of experiments was to confirmthe estimated reduction of the MHD pressure drop by the $\mathrm{FCl}$. The theoretical predictions for the pressure drop reduction factor $R_{2 D}$ based on the fully developed flow model as mentioned earlier is up to 100 and that using the full 3D model for the finitelength $\mathrm{FCl}$ is around 1.5. Figure 9shows the pressure drop measurements over the $30-\mathrm{cm}$ section of the bare duct (without the $\mathrm{FCl}$ ) collected at three magnetic fields and various velocities. These pressure drop measurements are in a good agreementwith numerical computations and the theoretical formula by Miyazaki [33] (just slightly higher), demonstrating reliability of the employed pressure measurement technique. Surprisingly, the measured pressure drop in the flow with the $\mathrm{FCl}$ does not match the theoretical predictions as shown in Fig. 10 where the measured MHD pressure drop in the flows with and without the $\mathrm{FCl}$ are plotted together versus the flowrate $Q$. This figure suggests the pressure drop reduction factor of only about 0.75 (i.e. the pressure drop in the flow with the $\mathrm{FCl}$ is higher compared to the bare duct flow). These unexpected resultscan be related to degradation of electroinsulating properties of the $\mathrm{FCl}$ caused byliquid metal ingress into the porous structure through the defects in the protective CVD layer.

After finishing the experiments, the loop was drained and the $\mathrm{FCl}$ extracted from the host duct (Fig. 11). Visual inspection of the $\mathrm{FCl}$ did not demonstrate any cracks in the protective CVD layer but theFCl weight was found to be $3022 \pm 1 \mathrm{~g}$, i.e. the mass gain was $2242 \mathrm{~g}$ compared to the originalweight. This mass gain, which is obviouslyrelated to the $\mathrm{PbLi}$ ingress, corresponds to $31 \%$ of the total $\mathrm{FCl}$ volume. For 
further characterization of the PbLi ingress into the $\mathrm{FCl}$, a few 1-cm slices were cut and then analyzed using an optical microscope. Three micrographs corresponding to the $\mathrm{FCl}$ inlet, middle section and outlet are shown in Fig. 11.

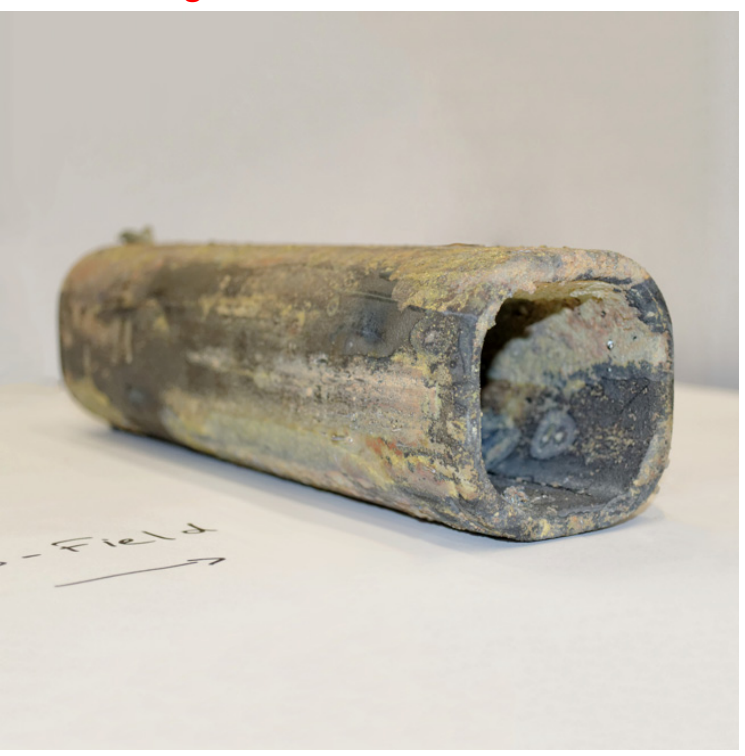

Figure 11. Picture of the $\mathrm{FCl}$ extracted from the duct.

(b)

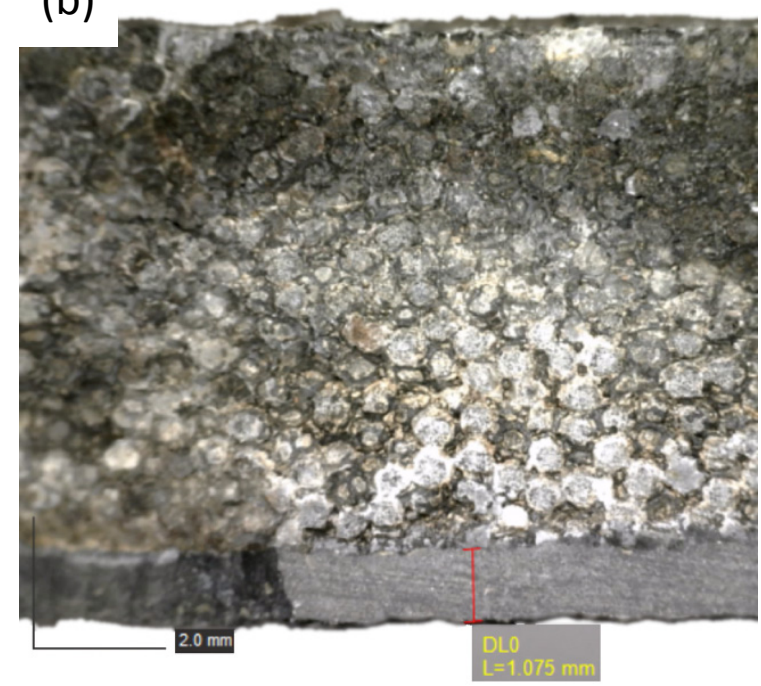

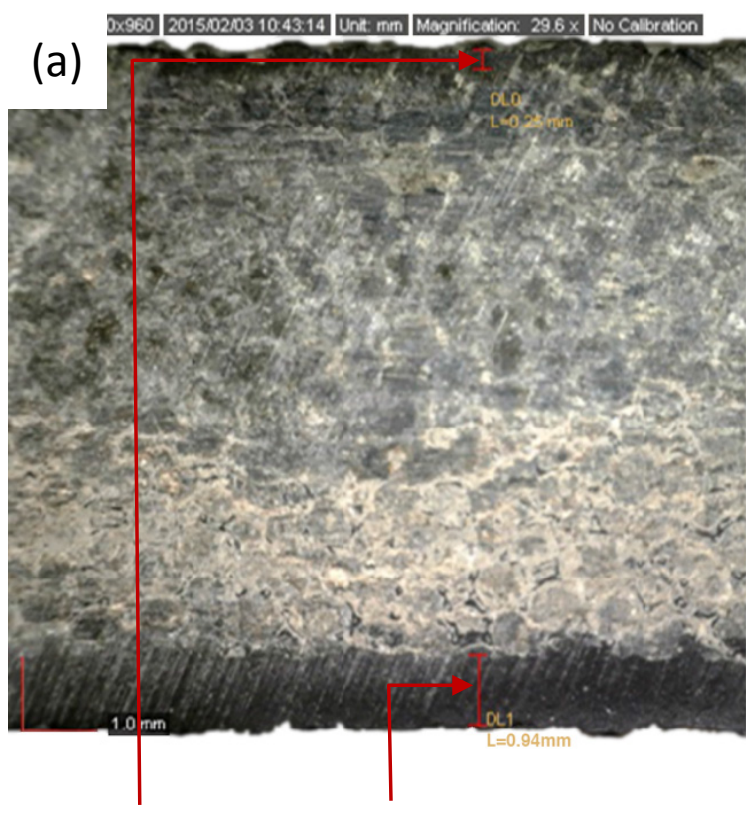

Inner CVD layer Outer CVD layer

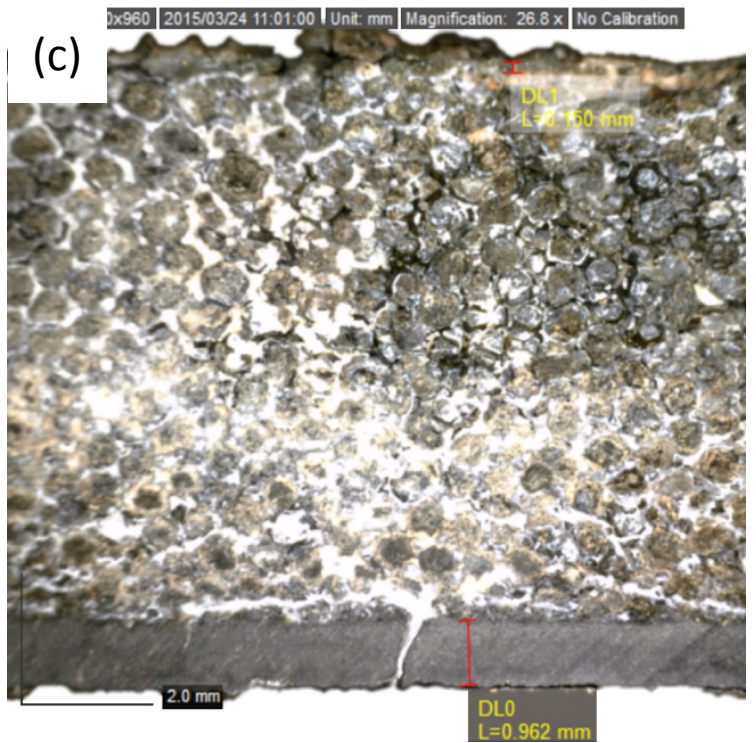

Figure 12. $\mathrm{FCl}$ micrographs of the $\mathrm{FCl}$ sample exposed to $\mathrm{PbLi}$ in the dynamic experiment taken at three different locations: (a) $1 \mathrm{~cm}$ from the $\mathrm{FCl}$ inlet on the Hartmann wall, (b) in the middle of the $\mathrm{FCl}$ on the side wall, and (c) $1 \mathrm{~cm}$ from the outlet on the Hartmann wall.

All three micrographs clearly demonstrate significant PbLi ingress. However, the micrograph taken from the inlet section demonstrates higher PbLi ingress compared to two other slices. This may indicate to some relation between the ingress and the MHD flow development effects at the $\mathrm{FCl}$ inlet. It also should 
be mentioned that no significant differences in the micrographs were found between the Hartmann and the side $\mathrm{FCl}$ walls meaning no anisotropy occurred in the transport phenomena that might be caused by the applied magnetic field. The thickness of the inner CVD layer was found to be significantly smaller compared to the outer layer. Whereas the outer layer is always about 1-mm thick, the inner layer was found to be non-uniform and several times thinner (Fig. 12b) and even almost absent at some locations. This may suggest that the ingress occurred predominantly from the bulk flow inside the $\mathrm{FCl}$ box through the inner CVD layer. However, based on this microscopic analysis, itis not clear if the inner CVD layer was originally thinner than the outer one due to some flaws in the manufacturing process or it degraded during the long exposure of the $\mathrm{FCl}$ to the flowing PbLi.

(a)
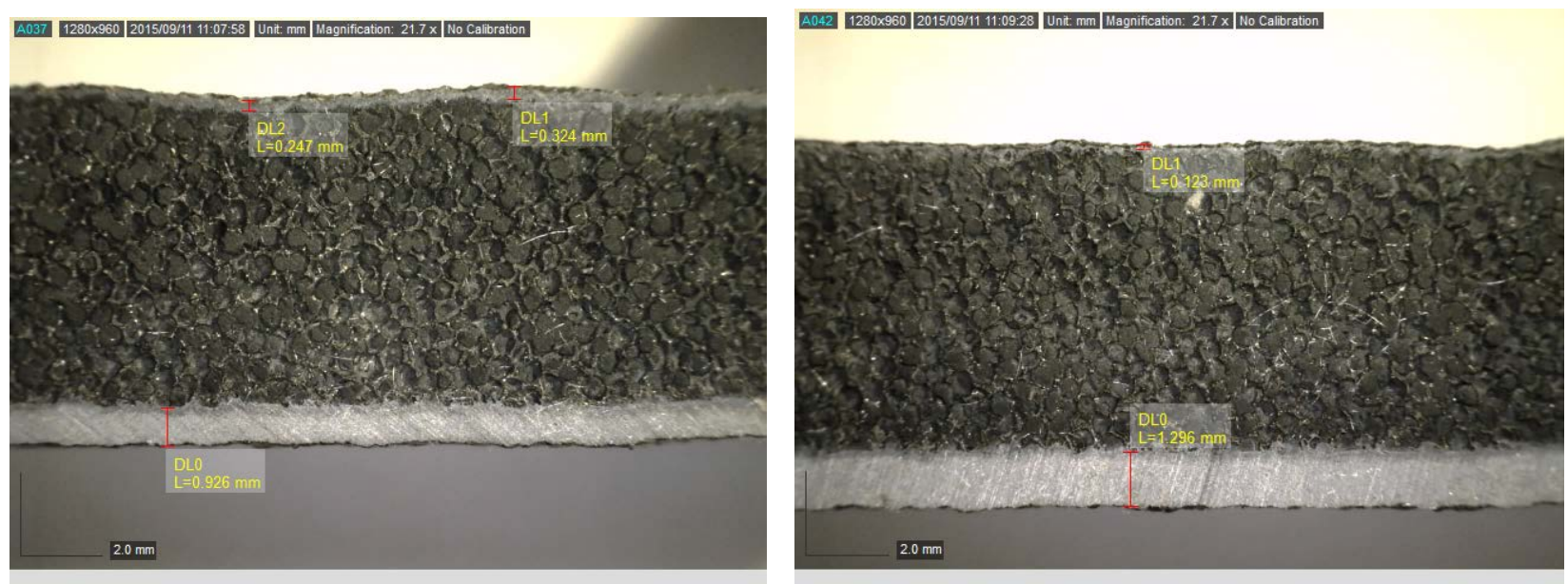

(b)

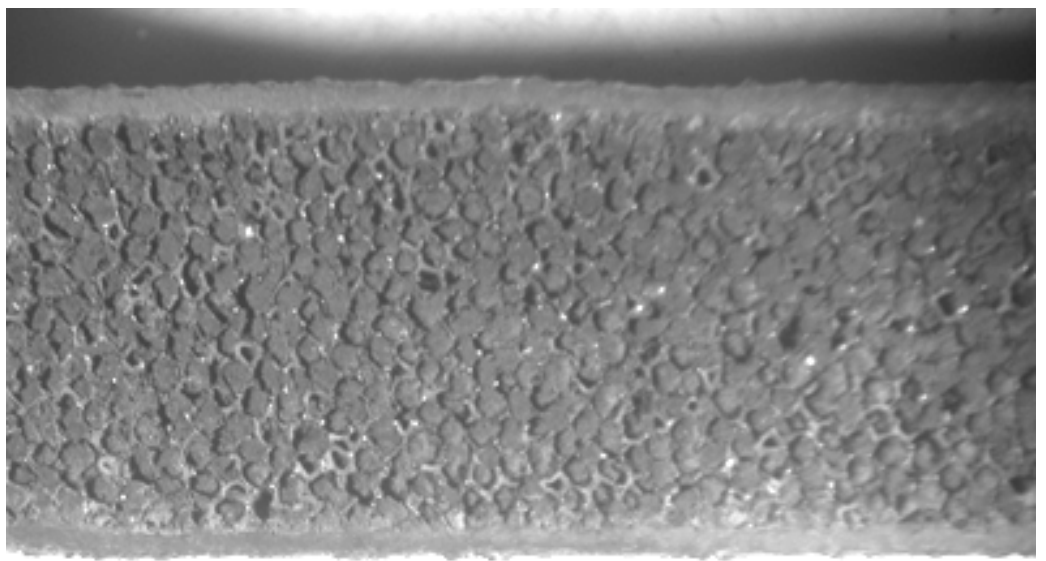

Figure 13. Micrographs of the unused $\mathrm{FCl}$ segments. (a) A cross-sectional cut of the $30-\mathrm{cm}$ segment shows variations of the inner CVD layer (at the top) from 0.1 to $0.3 \mathrm{~mm}$ compared to the outer layer of $\sim 1 \mathrm{~mm}$. (b) Cross-section of carbon aerogel-filled SiC foam tube (12 cm long) shows both inner and outer SiC CVD layers to be $\sim 0.76 \mathrm{~mm}$. 
To possibly understand the cause of a small thickness of the inner CVD layer compared to the outer layer, an unused $\mathrm{FCl}$ segment of the same manufactured series was sliced and analyzed. Figure 13ashows that the inner CVD layer is really thinner than the outer one. Whereas the thickness of the outer CVD layer is about $1 \mathrm{~mm}$, the thickness of inner layer is between 100 and $350 \mu \mathrm{m}$. Regarding this difference between the inner and outer CVD layers, it was known prior to coating the $\mathrm{FCl}$ tubes that the outer layer would be somewhat thicker than the inner one because of the inherent difficulties in getting the CVD precursor gas to flow into the tube (particularly as the part length increased). A $1.0 \mathrm{~mm} \mathrm{SiC}$ facesheet thickness was targeted because previous work had shown that closeout of the foam surface porosity typically occurs at a $0.35 \mathrm{~mm}$ thickness. However, although post-coating dimensional inspection of the fairly rough ID surface showed the inner layer thickness was near the target, cross-sections of fulllength $(30 \mathrm{~cm})$ segments show that the desired thickness of the inner CVD layer was not achieved. This effect was not seen in the shorter $(12 \mathrm{~cm})$ segments used in the static tests as shown in Figure 13b. Additional process optimization of the inner SiC layer is therefore required for $30-\mathrm{cm}$ or longer segments. Investigation of alternative facesheet materials, such as thin, freestanding (non-bonded) layers of molybdenum sheet that are produced to fit snug over the inner and outer surfaces is also of interest. Use of non-bonded metal facesheets would minimize stress at the foam/facesheet interface and eliminate issues associated with vapor-deposited facesheets.

It it is obvious that the observed ingress is related to some defects or damages of the $\mathrm{FCl}$ segment, in particular of the protective CVD layer. In addition to the manufacturing flaws, there could be several causes that might lead to damages, such as stress concentration at the pins, vibration and/or forces exerted by the flowing $\mathrm{PbLi}$, insufficient preheating of the $\mathrm{FCl}$ segment coming in contact with hot $\left(300^{\circ} \mathrm{C}\right) \mathrm{PbLi}$, or corrosion/erosion processes. All these observations suggest that more $\mathrm{FCl}$ development work and more studies have to be done. It should also be mentioned that the experimental campaign took unexpectedly long time, about 9 months, over which the PbLi was always flowing. The pressure measurements presented in this paper were taken almost at the end of this period so that it is hard to conclude confidently if the ingress occurred at the beginning of the experiments or the observed mass gain was caused by continuous $\mathrm{PbLi}$ ingress in the course of the entire experimental campaign.

\section{Post-experimental numerical analysis}

In order to better interpret the experimental results, a post-experimental numerical analysis was carried outusing two computational tools: first, commercially available code COMSOL [29], and second, a UCLA research code for fully developed MHD duct flows [30]. Using these two computational tools, two possible scenarios of $\mathrm{PbLi}$ ingress into the $\mathrm{FCl}$ and associated degradation of electro-insulating properties resulting in higher MHD pressure drop were considered. The first scenario assumes that the CVD layer has many micro cracks, which could appear as a result of a thermal shock when the $\mathrm{FCl}$ sample was exposed to high-temperature PbLi. In the second scenario, we assumed that the CVD layer is damaged only at a few particular locations, for example at the contact points between the $\mathrm{FCl}$ and the centering pins, such that the PbLi ingress occured at these locations while themost of theCVD facesheetwas still functioning as a good barrier to PbLi ingress.

\subsection{Numerical analysis using COMSOL}

A commercial multi-physics package COMSOL [29] iswell suitedfor computations of complex geometry flows. Moreover, it has been demonstrated recently that COMSOL can be effectively applied 
to MHD flows. The COMSOL code was validated against MHD benchmark problems endorsed by the fusion community [35]. The numerical error in COMSOL in the benchmark case A (fully developed MHD flows) and $B$ (flows in a fringing magnetic field) proposed in [35] are less than $1 \%$ and $5 \%$ respectively.In the present 3D computations by COMSOL, a mathematical formulation based on the electric potential as the main electromagnetic variable was used to compute the induced electric currents in the conducting domain,including the liquid metal, $\mathrm{FCl}$ and electrically conducting host duct and then to couple these currents with the fluid flow. The COMSOL code that utilizes finite-element discretization solves theNavier-Stokes equationsand the elliptic-type equation for the electricpotential separately through a segregated approach and then both the outputs at each numerical time step are coupled. The basic linear system of equations is solved through the Newton-Raphson method. A similar approach was used successfully in [34] to solve a number of LM MHD problems.

(a)

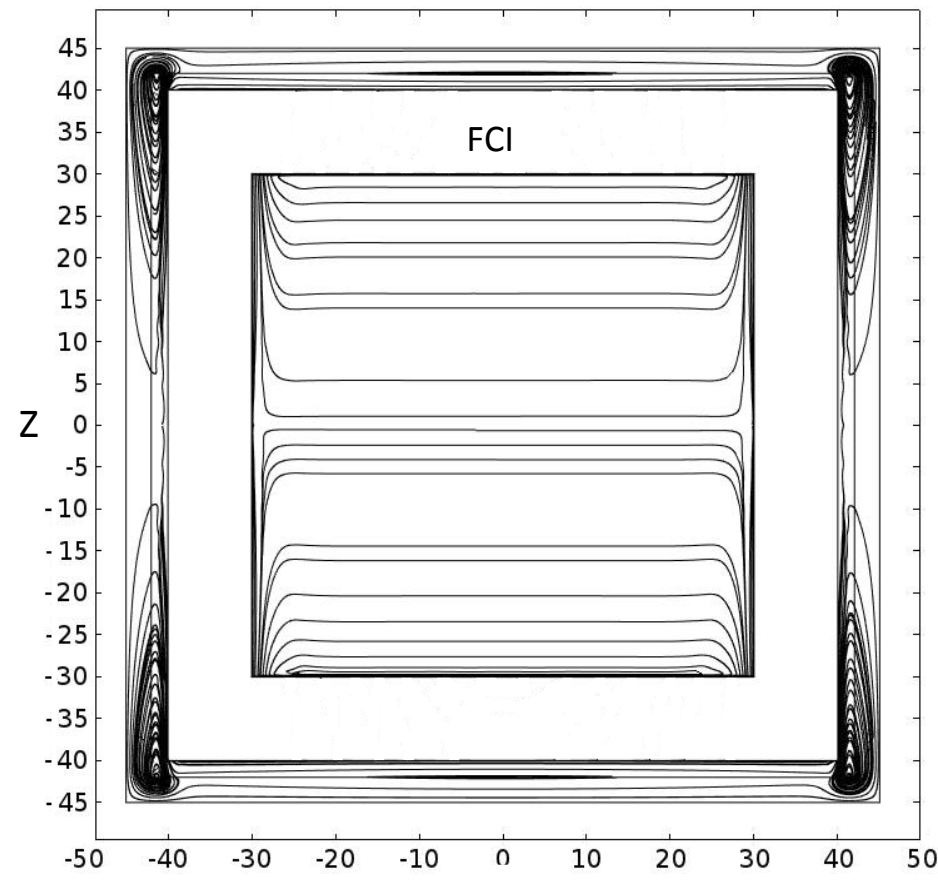

(b)

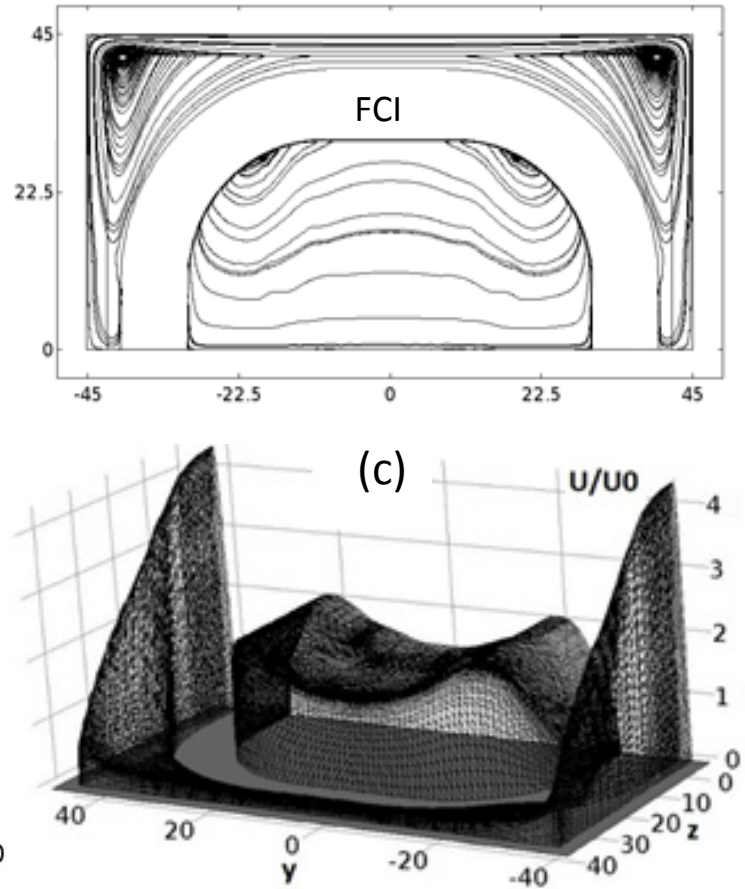

Figure 14. Comparison between $\mathrm{MHD}$ computations for rounded corner and right-angled corner $\mathrm{FCl}$ at $B=1.0 \mathrm{~T}(\mathrm{Ha}=895), U_{0}=10 \mathrm{~cm} / \mathrm{s}(\operatorname{Re}=22,700)$ and $\sigma_{\mathrm{FCl}}=5 \mathrm{~S} / \mathrm{m}:$ (a) electric current streamtracers in the flow with right-angled corner $\mathrm{FCl}$, (b) in the flow with rounded corner $\mathrm{FCl}$, and (c) velocity profile in the flow with rounded corner $\mathrm{FCl}$. The magnetic field is in Z-direction. Both $\mathrm{Z}$ and $\mathrm{Y}$ in $\mathrm{mm}$.

For simulating the $\mathrm{FCl}$ cases, a full 3D geometry including $\mathrm{FCl}$ rounded corners was included in the computational model, but taking into account the flow symmetry only half of the host duct cross-section was employed in the computations to reduce the computational time. In all computed cases, the duct length of $0.8 \mathrm{~m}$ under uniform magnetic field was considered. A COMSOL built-in mesh generator was used to construct a non-uniform mesh with 5 mesh elements within the Hartmann layer and 7 elements within the side layer. Outside the boundary layers, the mesh size is geometrically increased inwards. The following boundary conditions are applied: zero normal component of the electric current at all outer 
surfaces, flat velocity profile at the inlet, zero $\partial u / \partial x$ and zero pressure at the outlet, no-slip condition at the liquid-wall interface, and symmetry condition at the middle of the cross-section.

One of the initial guesses to explain the two times higher computed pressure drop reduction factor compared to the experiment was the effect of $\mathrm{FCl}$ rounded corners, which was not accounted in the preexperimental analysis. However, including the rounded corners into the computational model in the post-experimental analysis has not revealed substantially new flow features. Figure 14shows the induced electric current in the cross-sectional area of the duct at $21 \mathrm{~cm}$ downstream from the $\mathrm{FCl}$ inlet. Comparison is made between the case for rounded corners and that for the right-angled corner $\mathrm{FCl}$. In the reference cross-section, the flow is fully developed such that the current distribution and the velocity profile are very similar between the two cases. Namely, the electric current is generated in the core flow inside the $\mathrm{FCl}$ box and then the current is closed through the Hartmann and side layers. Some currents are also generated in the gap region but these currents are smaller than those in the PbLi flow inside the $\mathrm{FCl}$. A quantitative comparison of the MHD pressure drop between the two computations also suggests a higher than unity $\mathrm{R}$-factor regardless the $\mathrm{FCl}$ shape: $R=1.37$ for the sharp corners and $R=1.39$ for the $\mathrm{FCl}$ with rounded corners (for $\mathrm{Ha}=895$ and $\mathrm{Re}=22,700$ ). Therefore, the unexpectedly small magnitude of the R-factor observed in the experiment is not related to the corner shape but should be attributed to the PbLi ingress.

(a)

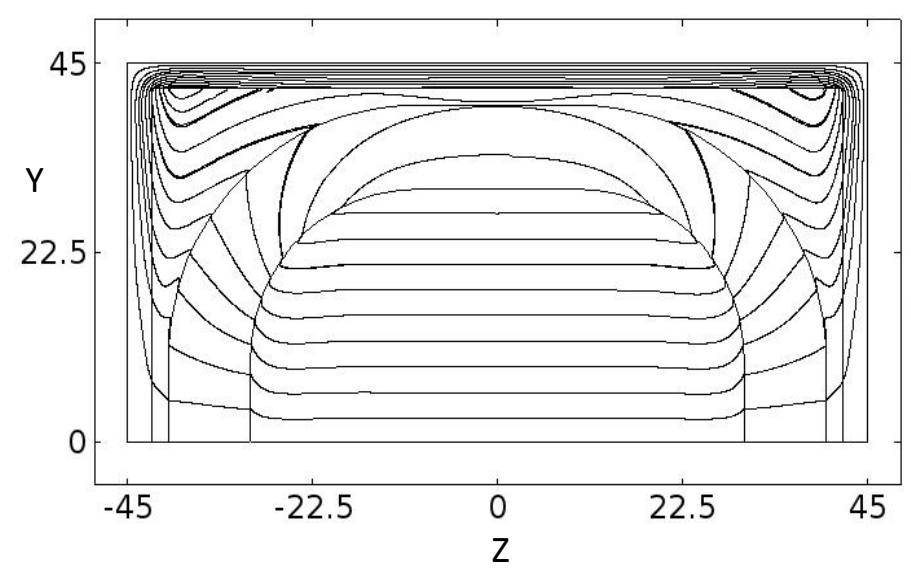

(b)

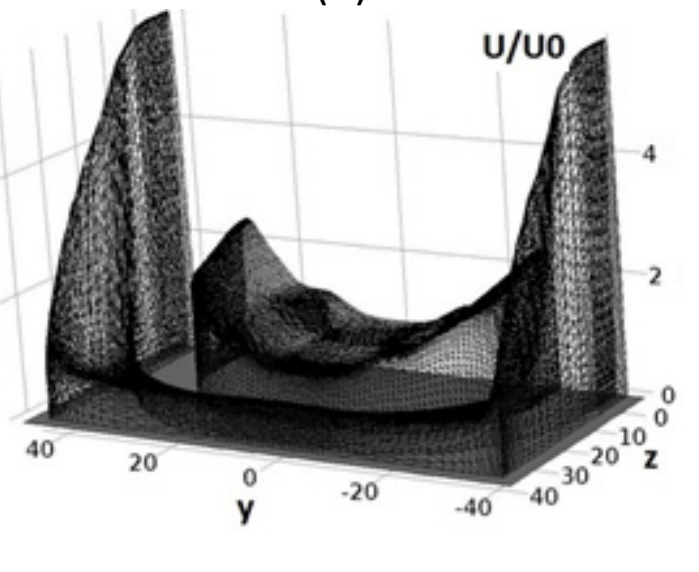

Figure 15. Computed MHD flow in a rectangular duct with a conducting rounded corner $\mathrm{FCl}$ at $B=1.0 \mathrm{~T}(\mathrm{Ha}=895), U_{0}=10 \mathrm{~cm} / \mathrm{s}(\mathrm{Re}=22,700)$ and $\sigma_{\mathrm{FCl}}=64,000 \mathrm{~S} / \mathrm{m}:$ (a) electric current streamtracers and (b) velocity profile. The magnetic field is in Z-direction. Both $\mathrm{Z}$ and $\mathrm{Y}$ in $\mathrm{mm}$.

The next computational effortusing COMSOLwas taken to evaluate the effective electrical conductivity of the $\mathrm{FCl}$ by matching measured and computed pressure drops. The physical model behind these computations assumes that the entire $\mathrm{FCl}$ is uniformly soaked with $\mathrm{PbLi}$ through many micro cracks in the CVD layer. As a result of the PbLi ingress, both the bulk material and the CVD layer have high electrical conductivity, which is lower than the electrical conductivity of PbLi but sufficiently higher than the electrical conductivity of both the original undamaged CVD layer and that of the bulk material. Numerically, theelectrical conductivity of the $\mathrm{FCl}$ was varied until the numerical pressure reduction factor matched the experimental value. As a first step, $\sigma_{F C I}$ was set equal to $\sigma_{\text {PbLi }}$ such as to get an upper extreme case of PbLi ingress inside the $\mathrm{FCl}$. The $\sigma_{F C I}=5 \mathrm{~S} / \mathrm{m}$ can be considered as the lower extreme case with no PbLi ingress. With few iterations of $\sigma_{\mathrm{FCI}}$ in the numerical model, $\sigma_{F C I}=64,000 \mathrm{~S} / \mathrm{m}$ was 
found to provide good match with the experiment at maximum deviation of $12 \%$ at $0.5 \mathrm{~T}$ as shown in Table II.Corresponding current and velocity distributions are shown in Fig. 15.

Table II. Evaluation of the effective $\mathrm{FCl}$ electrical conductivity in the post-experimental analysis. Pressure drop reduction factor computed in COMSOL at different experimental magnetic fields is shown.

\begin{tabular}{|l|c|c|c|}
\hline & $B=0.5 \mathrm{~T}$ & $B=1.0 \mathrm{~T}$ & $B=1.5 \mathrm{~T}$ \\
\hline$\sigma_{F C I}(\mathrm{~S} / \mathrm{m})$ & 64000 & 64000 & 64000 \\
\hline$U_{0}(\mathrm{~cm} / \mathrm{s})$ & 10 & 10 & 10 \\
\hline$R_{3 \mathrm{~d}}$, numerical & 0.64 & 0.75 & 0.81 \\
\hline$R_{3 \mathrm{~d}}$, experimental & 0.73 & 0.74 & 0.79 \\
\hline Relative error $(\%)$ & 12.3 & 1.4 & 2.5 \\
\hline
\end{tabular}
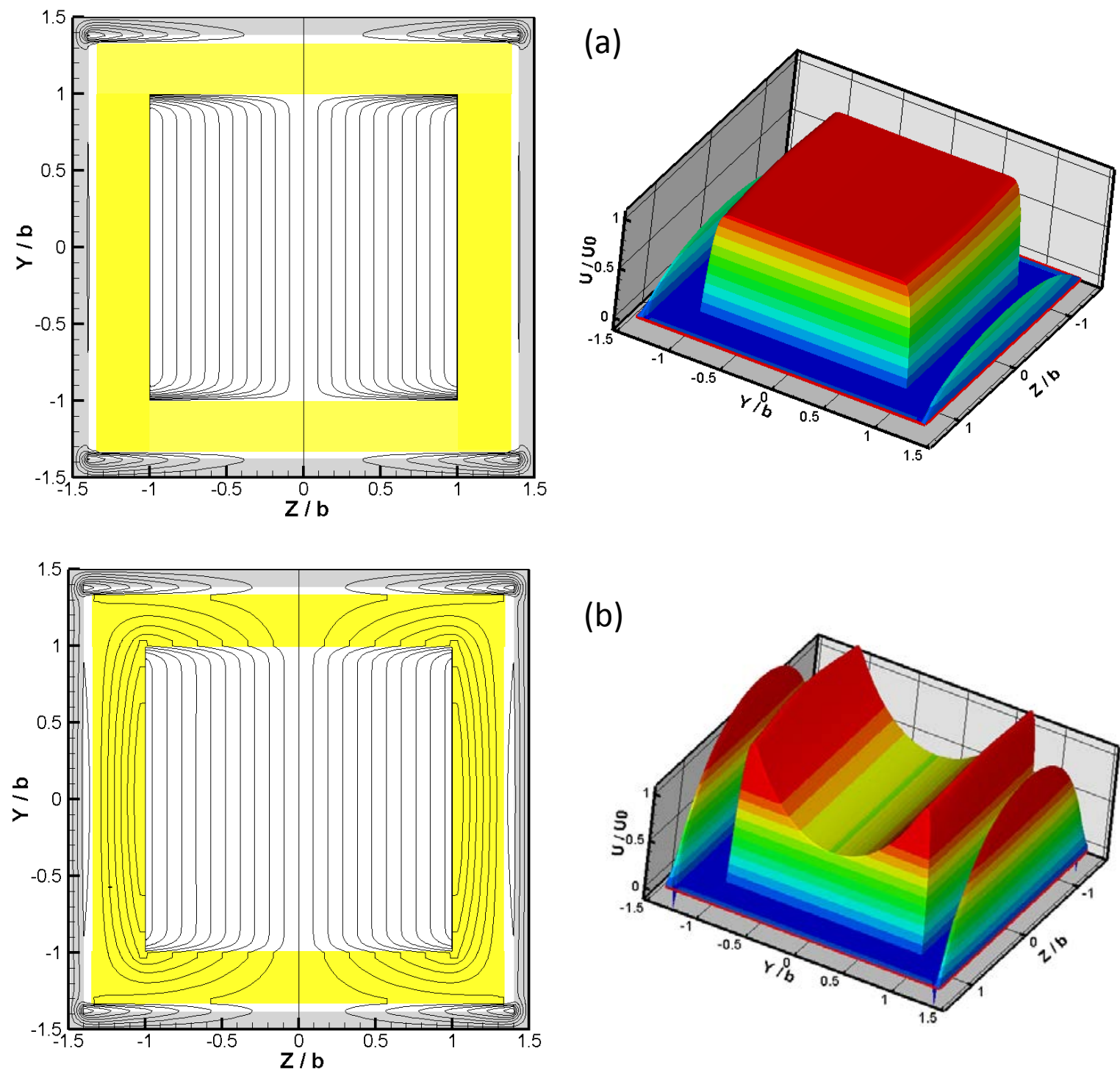

Figure 16. Comparison of the electric current streamtracers (left) and the velocity profile (right) in the fully developed flow with the $\mathrm{FCl}$ at the magnetic field of $1 \mathrm{~T}$ : (a) undamaged $\mathrm{FCl}$ and (b) damaged $\mathrm{FCl}$ leading to PbLi ingress in the $\mathrm{FCl}$ bulk material. Magnetic field in Z-direction. Both inner and outer CVD layers are 1-mm thick. 


\subsection{Numerical analysis using UCLA code}

The home-made research UCLA code [31] is limited to fully developed MHD flows. That is why the results obtained with this code cannot be directly compared with the experimental results, which involve both 2D and 3D effects as explained earlier in Section 2. However, the code is well suited for multi-material computations and allows for very fast computations compared to COMSOL and HIMAG and thus can serve as an effective modelling tool to address certain aspects of the experimental flows. Namely, in this effort a proposed physical model assumes that the CVD layer is mostly undamaged except for a few locations where PbLi ingress occurred, for example, at the points of contact between the centering pins and the $\mathrm{FCl}$.

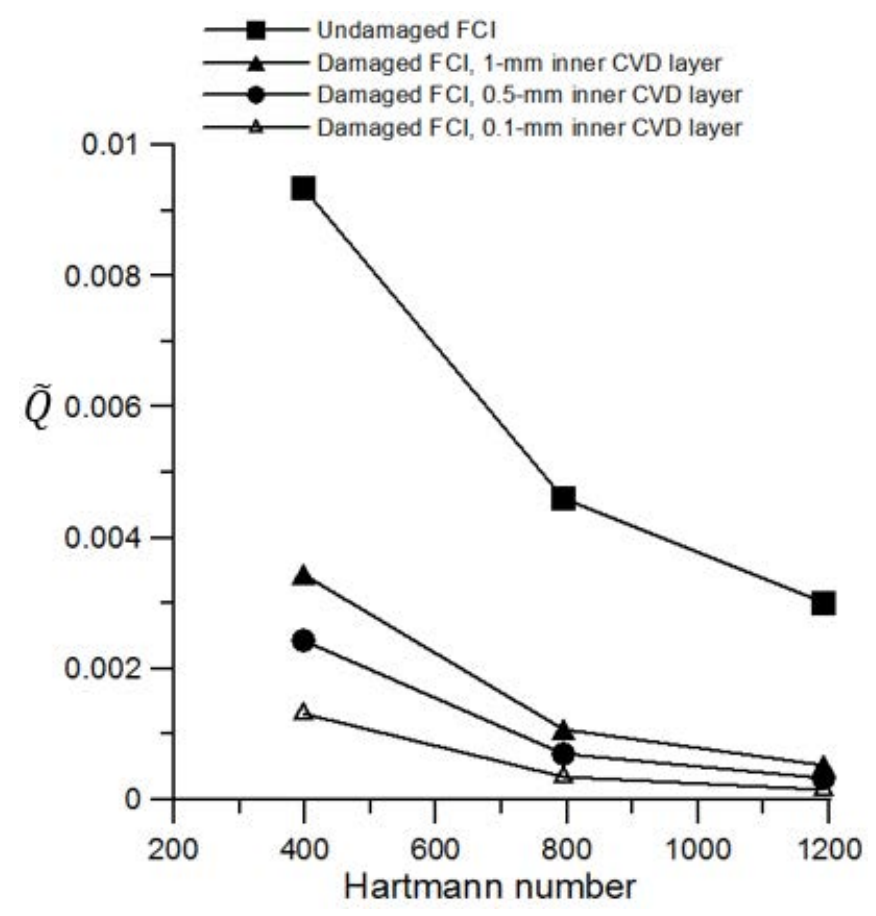

Figure 17. Effect of the thickness of the inner CVD layer on the dimensionless flow rate $Q$.

Taking into account a very long exposure time in the experiments, the PbLi that penetrated through these local defects in the bulk material could further diffuse and saturate the entire SiC foam-based core resulting in high electrical conductivity. In the computations, the $\mathrm{FCl}$ is considered as a "sandwich" structure, which includes inner and outer CVD layers and the core region. The electrical conductivity of the CVD layer in the computations is $100 \mathrm{~S} / \mathrm{m}$ and that of the core is $5 \mathrm{~S} / \mathrm{m}$ in the case of no ingress and $64,000 \mathrm{~S} / \mathrm{m}$ in case the $\mathrm{FCl}$ is soaked with $\mathrm{PbLi}$, similar to that in the COMSOL computations in Section 7.1. The outer $\mathrm{FCl}$ layer in all the computations is $1 \mathrm{~mm}$ thick, while the thickness of the inner layer was varied from 1 to $0.1 \mathrm{~mm}$ as there are some evidences that the inner layer was unintentionally manufactured thinner than the outer one as explained in Section 6 . The computations are limited to fully developed flow conditions, i.e. the 3D effects associated with the $\mathrm{FCl}$ edges are not captured. Comparisons between the case of ideal $\mathrm{FCl}$ (undamaged $\mathrm{FCl}$ ) and that with some local defects in the $\mathrm{FCl}$ layer (damaged $\mathrm{FCl}$ ) are shown in Fig. 16 for the velocity profile and the induced electric current. For the 
undamaged $\mathrm{FCl}$, all currents generated in the $\mathrm{PbLi}$ flow inside the $\mathrm{FCl}$ box remain localized to the flow domain and the velocity is uniform except for the thin MHD boundary layers. The case of a damaged $\mathrm{FCl}$ demonstrates a different current path where the induced electric current crosses the CVD layer at almost the right angle and then flows near tangentially inside the $\mathrm{FCl}$. The associated velocity structure shows higher velocities near the $\mathrm{FCl}$ walls parallel to the magnetic field (known as near-wall jets) and high velocities in the two gap sections parallel to the magnetic field, while the flow is stagnant in the two other gap sections.

In the next computations, the effect of the thickness of the inner $\mathrm{FCl}$ layer on the MHD pressure drop was addressed in a parametric analysis. Figure 17shows the influence of the magnetic field (Hartmann

number) and the thickness of the inner CVD layer on the dimensionless flow rate $\tilde{Q}=\int_{-1}^{1} d \tilde{y} \int_{-1}^{1} \widetilde{U} d \tilde{z}$, where $\tilde{z}=z / b, \tilde{y}=y / b$ and the dimensionless axial velocity is defined as $\widetilde{U}=U /\left[b^{2} v^{-1} \rho^{-1}(-d P /\right.$ $d x)$ ] using the pressure gradient in the liquid $d P / d x$. In this figure, the dimensionless flow rates for the damaged $\mathrm{FCl}$ at the thickness of the inner CVD layer of $0.1,0.5$ and $1.0 \mathrm{~mm}$ are compared with the flow rate in the flow with the undamaged $\mathrm{FCl}$. All damaged $\mathrm{FCl}$ cases show significantly lower $\widetilde{Q}$ (higher $\mathrm{MHD}$ pressure drop) compared to the undamaged $\mathrm{FCl}$ case. The maximum difference is of a factor of 5 in the case of 0.1-mm inner CVD layer. Although these computed results cannot be used in direct comparisons with the experimental results, the demonstrated tendencies suggest that the proposed model of the damaged $\mathrm{FCl}$ is quite realistic.

\section{Concluding remarks}

Theoretical predictions of the pressure drop reduction factor show that in the conditions of a DCLL blanket the $\mathrm{FCl}$ can reduce the MHD pressure drop up to 100 times providing that no PbLi ingress into the $\mathrm{FCl}$ occurred. The experimental studies that included static and dynamic tests of foam-based $\mathrm{SiC}$ samples in PbLi yet brought ambiguous results. In static tests, about half of the tested samples demonstrated no PbLi ingress while others, including CVD-coated and uncoated samples, showed some ingress from small to significant. Dynamic testing in the flowing PbLi was performed at different velocities (up to $9 \mathrm{~cm} / \mathrm{s}$ ) and magnetic fields (up to $1.5 \mathrm{~T}$ ) and the temperature of $300^{\circ} \mathrm{C}$. The dynamic tests have not confirmed yet the anticipated reduction of the MHD pressure drop because significant PbLi ingress occurred in the course of the experiment that caused degradation of electgroinsulating properties of the $\mathrm{FCl}$ as confirmed by the post-experimental weight and microscopic analysis. However, since the entire testing took a very long time ( $6500 \mathrm{hrs}$ ) and the test was not interrupted for inspection of the $\mathrm{FCl}$ segment, it is not clear when the ingress occurred, at the beginning or closer to the end of the experiment. Indirect estimates of the MHD pressure drop made in the first phase of the experiment ( $<800 \mathrm{hrs}$ ) suggest that at the beginning of the experiment the $\mathrm{FCl}$ did itsjob as an electrical insulator such that the ingress occurred in later stages of the experiment. It needs to be stressed that no $\mathrm{SiC} \mathrm{FCls}$ were manufactured and tested before, so that these first testing results do not provide a ground to cast any doubt on the $\mathrm{FCl}$ concept. However, these results indicate to some flaws in the manufacturing process that have to be corrected in the next efforts.Moreover, the obtained experimental data is a very valuable database to be used in sharpening the MHD computational tools and also to develop physical/mathematical models for MHD duct flows with an $\mathrm{FCl}$.

To possibly explain the pressure drop results in the experiment, two physical model were suggested. In the first model, the entire $\mathrm{FCl}$ was assumed to be highly electrically conducting, including the protective CVD facesheet due to the PbLi ingress into the $\mathrm{FCl}$ through microscopic cracks in the CVD layer. Using the COMSOL software, the best match between the measurements and the computational data for the pressure drop in the PbLi was found at the electrical conductivity of the $\mathrm{FCl}$ of $64,000 \mathrm{~S} / \mathrm{m}$, which is significantly higher than the electrical conductivity of the original foam-based $\mathrm{SiC} \mathrm{FCl}$ but at the 
same time two orders of magnitude lower than the electrical conductivity of PbLi. This is consistent with the $\mathrm{FCl}$ mass gain observed in the experiment, which was found to be equivalent to $31 \%$ of the total $\mathrm{FCl}$ volume filled with PbLi.

Another possible scenario of the $\mathrm{PbLi}$ ingress is that the CVD layer mainly retained its electroinsulating properties over the whole course of the experiment but the ingress occurred through the local defects in the CVD layer, for examples at the points of contact between the centering pins and the $\mathrm{FCl}$. Also, some local defects in the CVD layer might be formed as a result of the manufacturing process. The latter wasindirectly confirmed by the microscopic analysis of the unused $\mathrm{FCl}$ samples (not exposed to PbLi), which showed that the inner CVD layer was significantly thinner than the outer layer, at some locations reaching $~ 0.1 \mathrm{~mm}$. This scenario was also analyzed in numerical computations using a UCLA multi-material MHD code. The observed tendencies suggest that such a scenario of PbLi ingress is quite possible.

To conclude, more work is needed, including development of $\mathrm{SiC}$ materials and sealing layers that assure no $\mathrm{PbLi}$ ingress before implementing an $\mathrm{FCl}$ in a real fusion device.

\section{Acknowledgment}

This work was performed with support from the US Department of Energy, Office of Fusion Energy Sciences, under Grant No. DE-FG02-86ER52123. We acknowledge technical contributions from Damien Sutevski, Feng-Chen Li and Yoshitaka Ueki who were involved in the starting phase of the project.

\section{References:}

1. S. Smolentsev, N.B. Morley, M. Abdou, S. Malang, Dual-Coolant Lead-Lithium (DCLL) blanket status and R\&D needs, Fusion Eng. Des. 100, 44-54 (2015).

2. S. Malang, K. Schleisiek (Editors), Dual Coolant Blanket Concept, Kernforschugszentrum Karlsruhe, Karlsruhe, KfK 5424, 1994.

3. M.S. Tillack, S. Malang, High performance PbLi blanket, Proc.17th IEE/NPSS Symposium on Fusion Engineering, Vol. 2, 1000-1004, San Diego, California, Oct.6-10, 1997.

4. H. John, S. Malang, H. Sebening (Editors), DEMO-relevant Test Blankets for NET/ITER. Part 1: Self-cooled Liquid Metal Breeder Blanket, Kernforschugszentrum Karlsruhe, Karlsruhe, KfK4908, 1991.

5. S. Smolentsev, N. Morley, M. Abdou, MHD and thermal issues of the SiCf/SiC flow channel insert, Fusion Sci. Tech. 50, 107-119 (2006).

6. S. Smolentsev, Z. Xu, Ch. Pan, M. Abdou, Numerical and experimental studies of MHD flow in a rectangular duct with a non-conducting flow insert, Magnetohydrodynamics 46, 99-111 (2010).

7. D. Sutevski, S. Smolentsev, N. Morley, M. Abdou, 3D numerical study of MHD flow in a rectangular duct with a flow channel insert, Fusion Sci. Tech. 60 (2), 513-517 (2011).

8. S. Smolentsev, S. Malang, Double-layer flow channel insert for electric and thermal insulation in the dual-coolant lead-lithium blanket, Fusion Sci. Tech. 6, 201-205 (2009).

9. S. Smolentsev, R. Moreau, M. Abdou, Characterization of key magnetohydrodynamic phenomena in PbLi flows for the US DCLL blanket, Fusion Eng. Des. 83, 771-783 (2008).

10. S. Smolentsev, M. Abdou, N. B. Morley, M. Sawan, S. Malang, C. Wong, Numerical analysis of MHD flow and heat transfer in a poloidal channel of the DCLL blanket with a SiCf/SiC flow channel insert, Fusion Eng. Des. 81, 549-553 (2006).

11. X. Zhang, Z. Xu, C. Pan, Numerical analysis of MHD duct flow with a flow channel insert, Fusion Eng. Des. 85, 2090-2094 (2010). 
12. E. Mas de les Valls, L. Batet, V. de Medina, J. Fradera, M. Sanmartí, L.A. Sedano, Influence of thermal performance on design parameters of a He/LiPb dual coolant DEMO concept blanket design, Fusion Eng. Des. 87, 969-97368 (2012).

13. $\mathrm{M}$. Ni, Recent advances in computational techniques for MHD flow and application to fusion, Fusion Eng. Des. 87, 1544-1549 (2012).

14. C. Kim, Magnetohydrodynamic flows entering the region of a flow channel insert in a duct, Fusion Eng. Des. 89, 56-68 (2014).

15. S. Xu, N. Zhang, M. Ni, Influence of flow channel insert with pressure equalization opening on MHD flows in a rectangular duct, Fusion Eng. Des. 88, 271-275 (2013).

16. M. J. Pattison, S. Smolentsev, R. Munipalli, M. Abdou, Tritium transport in poloidal flows of a DCLL blanket, Fusion Sci. Technol. 60, 809-813(2011).

17. $\mathrm{H}$ Zhang, A Ying, M Abdou, Impact of pressure equalization slot in flow channel insert on tritium transport in a DCLL-type poloidal duct, Fusion Sci. Technol. 64, 651-656(2013).

18. S. Saeidi, Study of MHD Corrosion and Transport of Corrosion Products of Ferritic/Martensitic Steels in the Flowing PbLi and its Application to Fusion Blanket, Ph.D. Dissertation, UCLA, 2014.

19. D. Sutevski, S. Smolentsev, M. Abdou, 3D Numerical study of pressure equalization in MHD flow in a rectangular duct with insulating flow channel insert, Fusion Eng. Des. 89, 1370-1374 (2014).

20. S. Smolentsev, N. B. Morley, C. Wong, M. Abdou, MHD and heat transfer considerations for the US DCLL blanket for DEMO and ITER TBM, Fusion Eng. Des. 83, 1788-1791 (2008).

21. S. Smolentsev, C. Wong, S. Malang, M. Dagher, M. Abdou, MHD considerations for the DCLL inboard blanket and access ducts, Fusion Eng. Des. 85, 1007-1011 (2010).

22. A.R. Raffray, R. Jones, G. Aiello, M. Billone, L. Giancarli, H. Golfier et al., Design and material issues for high performance SiCf/SiC-based fusion power cores, Fusion Eng. Des. 55, 55-95 (2001).

23. S. Sharafat, A. Aoyama, N. Morley, S. Smolentsev, Y. Katoh, B. Williams, N. Ghoniem, Development status of a SiC-foam based flow channel insert for a U.S.-ITER DCLL TBM, Fusion Sci. Tech. 56, 883-891 (2009).

24. B.A. Pint, Compatibility issues for a high temperature dual coolant blanket, Fusion Sci. Technol. 52, 829-833 (2007).

25. B.A. Pint, Overview of coating and compatibility research for Fusion Energy in the US, Material Science Forum, Vols. 595-598, 549-558 (2008).

26. Z.Q. Zhu, Q.Y. Huang, S. Gao, X.G. Zhou, X.Z. Ling, Y.P. Chen, M.L. Zhang, Y. Song, Y.L. Wang, Z.F. Zhang, S. Zhao, M.C. Kong, Preliminary experiment on compatibility of SiCf/SiC composites in static LiPb at $700^{\circ} \mathrm{C}$, Fusion Eng. Des. 84, 2048-2051 (2009).

27. S. Smolentsev, F.-C. Li, N. Morley, Y. Ueki, M. Abdou, T. Sketchley, Construction and initial operation of MHD PbLi facility at UCLA, Fusion Eng. Des. 88, 317-326 (2013).

28. S. Smolentsev, N. B. Morley, M. Abdou, R. Munipalli, R. Moreau, Current approaches to modeling MHD flows in the dual coolant lead lithium blanket, Magnetohydrodynamics 42, 225236 (2006).

29. COMSOL reference manual, version 4.4

30. S. Smolentsev, N. Morley, M. Abdou, Code development for analysis of MHD pressure drop reduction in a liquid metal blanket using insulation technique based on a fully developed flow model, Fusion Eng. Des. 73, 83-93 (2005).

31. S. Smolentsev, N. Vetcha, M. Abdou, Effect of a magnetic field on stability and transitions in liquid breeder flows in a blanket, Fusion Eng. Des. 88, 607-610 (2012).

32. J. Sommeria and R. Moreau, Why, how, and when MHD turbulence becomes two-dimensional, J. Fluid Mech.118, 507-518 (1982). 
33. K. Miyazaki, S. Inoue, N. Yamaoka, MHD pressure drop of liquid metal flow in circular and rectangular ducts under transverse magnetic field, pp. 29-36. Liquid Metal Magnetohydrodynamics, edited by J.J. Lielpeteris and R.J. Moreau, Kluwer, 1989.

34. N. Salah, A. Soulaimani, W. Habashi, A finite element method for magnetohydrodynamics, Comput. Methods Appl. Mech. Engrg. 190, 5867-5892 (2001).

35. S. Smolentsev, S. Badia, R. Bhattacharyay, L. Bühler, L. Chen, Q. Huang, H.-G. Jin, D. Krasnov, D.W. Lee, E. Mas de les Valls, C. Mistrangelo, R. Munipalli, M.-J. Ni, D. Pashkevich, A. Patel, G. Pulugundla, P. Satyamurthy, A. Snegirev, V. Sviridov, P. Swain, T. Zhou, et al., An approach to verification and validation of MHD codes for fusion applications, Fusion Eng. Des. 100, 65-72 (2015). 